OPEN ACCESS

Edited by:

Li-Rong Shao,

Johns Hopkins University,

United States

Reviewed by:

Hongtao Ma,

Cornell University, United States

Eva Maria Jimenez-Mateos,

Royal College of Surgeons in Ireland,

Ireland

Fahmeed Hyder

Yale University, United States

*Correspondence:

Richard Kovács

richard.kovacs@charite.de

Received: 15 June 2018

Accepted: 12 September 2018

Published: 08 October 2018

Citation:

Kovács R, Gerevich Z

Friedman A, Otáhal J, Prager O,

Gabriel S and Berndt N (2018)

Bioenergetic Mechanisms of Seizure

Control. Front. Cell. Neurosci. 12:335.

doi: 10.3389/fncel.2018.00335

\section{Bioenergetic Mechanisms of Seizure Control}

\author{
Richard Kovács ${ }^{1 *}$, Zoltan Gerevich ${ }^{1}$, Alon Friedman ${ }^{2,3}$, Jakub Otáhal' ${ }^{4}$, Ofer Prager ${ }^{2}$, \\ Siegrun Gabriel ${ }^{1}$ and Nikolaus Berndt ${ }^{5,6}$
}

${ }^{1}$ Charité - Universitätsmedizin Berlin, Corporate Member of Freie Universität Berlin, Humboldt-Universität zu Berlin, and Berlin Institute of Health, Institut für Neurophysiologie, Berlin, Germany, ${ }^{2}$ Departments of Physiology and Cell Biology, Cognitive and Brain Sciences, The Zlotowski Center for Neuroscience, Ben-Gurion University of the Negev, Beersheba, Israel, ${ }^{3}$ Department of Medical Neuroscience, Faculty of Medicine, Dalhousie University, Halifax, NS, Canada, ${ }^{4}$ Institute of Physiology, Czech Academy of Sciences, Prague, Czechia, ${ }^{5}$ Charité - Universitätsmedizin Berlin, Corporate Member of Freie Universität Berlin, Humboldt-Universität zu Berlin, and Berlin Institute of Health, Institut für Biochemie, Berlin, Germany, ${ }^{6}$ Charité - Universitätsmedizin Berlin, Corporate Member of Freie Universität Berlin, Humboldt-Universität zu Berlin, and Berlin Institute of Health, Institute for Computational and Imaging Science in Cardiovascular Medicine, Berlin, Germany

Epilepsy is characterized by the regular occurrence of seizures, which follow a stereotypical sequence of alterations in the electroencephalogram. Seizures are typically a self limiting phenomenon, concluding finally in the cessation of hypersynchronous activity and followed by a state of decreased neuronal excitability which might underlie the cognitive and psychological symptoms the patients experience in the wake of seizures. Many efforts have been devoted to understand how seizures spontaneously stop in hope to exploit this knowledge in anticonvulsant or neuroprotective therapies. Besides the alterations in ion-channels, transmitters and neuromodulators, the successive build up of disturbances in energy metabolism have been suggested as a mechanism for seizure termination. Energy metabolism and substrate supply of the brain are tightly regulated by different mechanisms called neurometabolic and neurovascular coupling. Here we summarize the current knowledge whether these mechanisms are sufficient to cover the energy demand of hypersynchronous activity and whether a mismatch between energy need and supply could contribute to seizure control.

Keywords: seizure, lactate, adenosine, neurometabolic coupling, neurovascular coupling, pericyte

\section{INTRODUCTION}

Epilepsy is a common neurological disease characterized by the manifestation of unprovoked seizures (Fisher et al., 2014). An epileptic seizure is "a transient occurrence of signs and/or symptoms due to abnormal excessive or synchronous neuronal activity in the brain" (Fisher et al., 2005). Seizures are represented by a stereotypic sequence of electroencephalographic events and associated clinical symptoms. Seizure termination can be described as a homeostatic self-limitation of the hypersynchronous activity, representing not a mere cessation but a characteristic change in the excitability of the nervous tissue. These changes evolve successively and may already start during the course of the seizure before the activity would terminate (Essig and Flanary, 1966). The current review focus on the contribution of altered energy metabolism to seizure control. For reviews on other anticonvulsant mechanisms mediated by intrinsic ion-channel modifications, changes in functional, network and synaptic properties of the neurons and effects of neuromodulators see Löscher and Köhling (2010) and Zubler et al. (2014). 
Seizures represent an extraordinary burden on the energy metabolism of the brain as restoration of the transmembrane ion gradients is mediated by energy consuming pump mechanisms. Thus, it is tempting to speculate that the metabolic changes that develop slowly during the course of a seizure might finally lead to the cessation of the hypersynchronous activity. Metabolic alterations may include altered substrate and oxygen availability, accumulation of metabolic intermediates and byproducts (such as adenosine, lactate and $\mathrm{CO}_{2}$ ) which in turn leads to activation of adenosine receptors, extracellular acidosis and opening of $\mathrm{K}_{\mathrm{ATP}}$ channels due to local shortage of ATP. These changes build up consecutively during the course of a seizure establishing conditions that not only contribute to the cessation of the activity but could potentially alter the normal neuronal functioning in the postictal phase. Conversely, disturbed energy metabolism could by itself favor seizure initiation by altering the ability of the tissue to recover transmembrane ion gradients following neuronal activity, as it is seen in mitochondrial encephalopathies (Kang et al., 2013; Zsurka and Kunz, 2015) or in mesial temporal lobe epilepsy (Rowley and Patel, 2013; Boison and Steinhäuser, 2018). Interictal hypoperfusion (Guillon et al., 1998; Suh et al., 2005; Geneslaw et al., 2011) and hypometabolism (Hetherington et al., 1995; Cendes et al., 1997; Hong et al., 2002) have been demonstrated in a wide range of epileptic syndromes including temporal lobe epilepsy, generalized childhood absence epilepsy and status epilepticus. Although seizure-induced cell loss and sclerotic modification of the tissue could partially explain the hypometabolic state, there is also evidence for dysfunction of the neurometabolic coupling (Kann et al., 2005) and oxidative damage of respiratory enzymes (Kunz et al., 2000; Vielhaber et al., 2003; Folbergrová and Kunz, 2012; Rowley and Patel, 2013). Lasting deficiencies in energy metabolism might underlie the frequent observation that "seizures-beget-seizures" (BenAri, 2001; Farrell et al., 2017b) by favoring the initiation of subsequent hypersynchronous activity (Zsurka and Kunz, 2015). Mismatch in the neurometabolic coupling might be responsible for seizure-associated cell loss via either free radical dependent or hypoxic mechanisms (Ingvar, 1986; Frantseva et al., 2000; Kovács et al., 2002; Rowley and Patel, 2013). Metabolic disturbances might also contribute to the development of pharmacoresistance, i.e., the incapability to prevent seizures with two or more antiepileptic therapy regimens directly or indirectly following sclerotic transformation of the tissue (Kovács and Heinemann, 2014). Thus, it is fundamental to understand the potentially proor anticonvulsant consequences of the seizure-associated changes in energy metabolism.

In the following we provide a short overview of the literature about the alterations of neurometabolic coupling during seizures and how these could contribute to seizure control. We discuss possible therapeutic targets which exploit metabolism-related mechanisms (2-deoxy-D-glucose (2DG), pyruvate, fructose 1,6 bisphosphate, ketogenic diet, $\mathrm{CO}_{2}$ inhalation, carbonic anhydrase inhibitors, adenosine 1 agonists). The last part is devoted to the mechanisms of seizure-induced neurovascular decoupling, which might be responsible for postictal hypometabolism and have been suggested to be associated with cognitive disturbances. We apologize that we cannot extensively discuss all aspects of seizure termination and regulation of neuronal energy metabolism as well as the anti-seizure mechanisms associated to caloric restriction and ketogenic diet.

\section{NEUROMETABOLIC COUPLING DURING ACUTE SEIZURES AND IN CHRONIC EPILEPTIC TISSUE}

Neuronal activity results in local changes in transmembrane ion-gradients, such as the increase in extracellular $\left[\mathrm{K}^{+}\right]$which is immediately countered by a concurrent increase in Na-KATPase activity (Lux et al., 1986). In order to keep pace with the ATP-demand of the ion-pump activity as well as that of the transport processes related to synaptic signaling (Liotta et al., 2012; Hall et al., 2012), energy metabolism has to adopt to the different neuronal activity states (Ames, 2000; Heinemann et al., 2002; Berndt et al., 2015). This neurometabolic coupling could operate via "pull" and "push" mechanisms, i.e., either as a consequence of alterations in ATP or other energy metabolism intermediates, or in a feed forward manner by activity dependent changes in intracellular and intramitochondrial $\mathrm{Ca}^{2+}, \mathrm{K}^{+}$and nitric oxide (NO) concentrations (Szewczyk et al., 2006; Denton, 2009). During physiological and interictal activity, changes in overall intracellular ATP concentration are expected to be rather small (see Seizure Associated Alterations in Energy Metabolism Intermediates and $\mathrm{pH}$ ). Yet, an increase in ATP utilization by the Na-K-ATPase leads to a concomitant increase in ADP and AMP concentration, as the adenylate kinase maintains a fast equilibrium between the adenine nucleotides. Assuming an ATP level of $3 \mathrm{mM}$ and an ADP level of $0.3 \mathrm{mM}$, even a minor decrease in ATP by $10 \%$ would decrease the ATP/ADP ratio from 10 to 4.5 and increase AMP levels more than fourfold. These changes in adenylates have immediate consequences for the regulation of energy metabolism (Figure 1). First, the adenine nucleotide translocator is activated leading to a decrease in mitochondrial ATP and mitochondrial membrane potential $(\psi)$ as the exchange of ATP (3 negative charges) for ADP (2 negative charges) is an electrogenic process. The shift in cytosolic and mitochondrial ATP/ADP ratio and the decrease in $\psi$ activate F0F1-ATPase, further draining the $\psi$. As a consequence, complexes IV, III, and I of the ETC are activated by associated shifts in the electron carriers, cytochrome $\mathrm{C}$ and ubiquinone $\left(\mathrm{QH}_{2}\right)$. This activation results in the initial oxidation shift in mitochondrial NADH, which can be observed by NADHautofluorescence (Kovács et al., 2001; Schuchmann et al., 2001; Berndt et al., 2015). The decrease in mitochondrial NADH activates the regulatory dehydrogenases of the tricarboxylic acid cycle as well as the pyruvate dehydrogenase reaction, thereby channeling pyruvate into the tricarboxylic acid cycle. At the same time, the glycolytic pathway is activated by the decreased ATP/ADP ratio and the increase in AMP at the glucokinase, phosphofructokinase and pyruvate kinase level, providing the pyruvate needed for increased aerobic metabolism. Normally, the increase in glycolytic activity exceeds the increase in aerobic metabolism and the excess pyruvate is exported in the form of lactate (Berndt et al., 2015). 


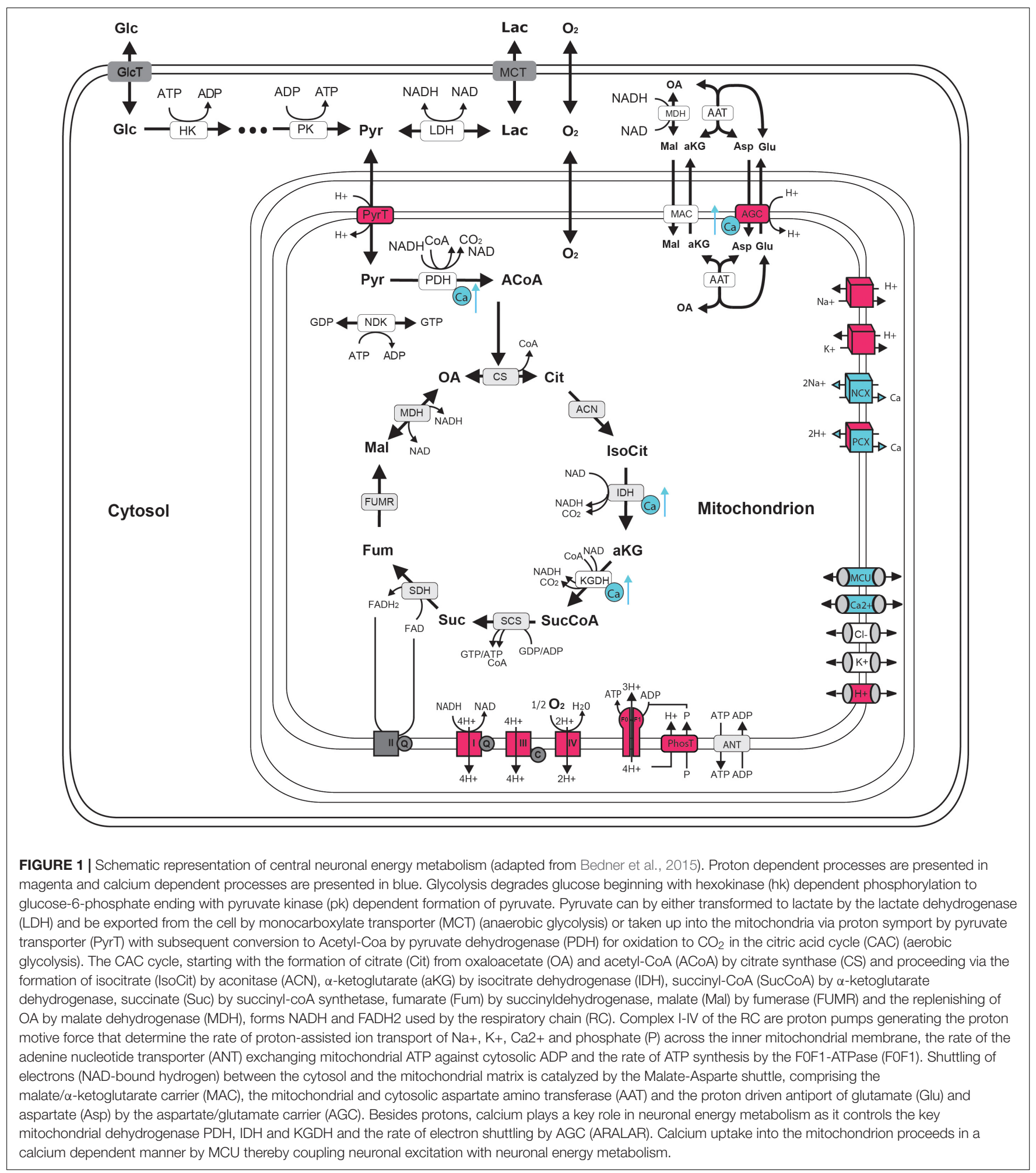

The "push" mechanisms, such as the mitochondrial $\mathrm{Ca}^{2+}$. cycle, are complementary in regulating energy metabolism (Kovács et al., 2005; Wei et al., 2011; Berndt et al., 2015; Nicholls, 2017; Kannurpatti, 2017). Neuronal firing and synaptic activity results in localized transient cytoplasmic $\mathrm{Ca}^{2+}$ increases, which are sequestered by mitochondria via the mitochondrial $\mathrm{Ca}^{2+}$ uniporter (MCU) channel complex leading to increased matrix $\mathrm{Ca}^{2+}$ concentration. Matrix $\mathrm{Ca}^{2+}$ plays a key regulatory role as it can enhance ETC in a potassium dependent manner (Szewczyk et al., 2006), increase aspartate malate shuttle and 
pyruvate supply (Gellerich et al., 2012; Rueda et al., 2014) and it is a positive modulator of three key dehydrogenases of the tricarboxylic acid cycle (TCA, McCormack et al., 1990; Denton, 2009), thereby leading to the enhanced formation of reducing equivalents (Figure 1). Typical biphasic changes in the redox state of flavin and adenine dinucleotides $\left(\mathrm{FADH}_{2}\right.$ and $\left.\mathrm{NADH}\right)$ can be observed following physiological stimulus in vivo (Kasischke et al., 2004) and during seizure-like events in brain slices consisting of an initial oxidation and a lasting reduction which outlasts the hypersynchronous activity (Schuchmann et al., 1999; Kovács et al., 2001). In this latter preparation enhanced $\mathrm{Ca}^{2+}$ cycling across the mitochondrial membrane during seizures has been shown to be responsible for the dissipation of $\psi$ (Kovács et al., 2005), although the contribution of the mitochondrial permeability transition induced by high mitochondrial $\mathrm{Ca}^{2+}$. load cannot be completely excluded (Kovac et al., 2012). While mitochondrial depolarization by definition decreases the proton motive force (composed of $\Delta \psi$ and $\Delta \mathrm{pH}$ ), it could also represent one way to enhance respiration (Malinska et al., 2010). Due to the fixed stoichiometry of the F0F1-ATPase of three protons per generation of one ATP, the decrease in proton motive force will have no energetic efficiency consequences as long as the energy of the three protons exceed the formation enthalpy of ATP. However, the $\psi$ dependence of the F0F1-ATPase activity leads to a strong activation and thereby increased ATP formation (see above). Thus, seizure termination in vitro seems to occur in the presence of enhanced energy metabolism, when neither the availability of the reducing equivalents nor oxygen could represent a limitation for the electrical activity (Schoknecht et al., 2017). However, in case of frequently recurring seizurelike events, which would resemble status epilepticus in vivo, signs of metabolic impairment develop in a free radical dependent manner (Kovács et al., 2002; Malinska et al., 2010; Zsurka and Kunz, 2015). Under these conditions seizure termination is impaired and the electrical activity transforms from seizure-like events to pharmacoresistant late recurrent discharges, indicating that the slowly developing energy crisis is rather pro-epileptic (Schuchmann et al., 1999; Ivanov et al., 2015). Seizure-associated enhancement of mitochondrial free radical formation might play an important role in the development of metabolic disturbances both in vitro (Frantseva et al., 2000; Kovács et al., 2002) and in vivo (Kunz et al., 2000; Vielhaber et al., 2003; Rowley and Patel, 2013). In addition, the seizure associated increase in NO formation was found primarily pro-epileptic as blockade of the neuronal NO synthase decreased severity of kainic acid induced seizures in vivo (Beamer et al., 2012) and delayed seizure onset in vitro (Schuchmann et al., 2002; Kovács et al., 2009). Unfortunately, it is not possible to unequivocally determine the contribution of NO-mediated inhibition of the electron transport chain complexes to the pro-epileptogenic effect (Ledo et al., 2010), as NO influences neuronal excitability and cerebral blood flow in many different ways.

Most of the aforementioned findings were obtained in experiments with acutely induced epileptiform activity in tissue samples of otherwise healthy animals. However, in chronic epileptic tissue the metabolic consequences of prior activity might influence the effects of seizures on energy metabolism.
Indeed, signs of metabolic impairment were evident in sclerotic hippocampal tissue from epilepsy patients as well as in the pilocarpine model of epilepsy, which may correspond to the hypoperfusion and hypometabolism in these areas (Kunz et al., 2000; Vielhaber et al., 2003; Kann et al., 2005). In conclusion, although metabolism related factors (see below) might contribute to seizure termination, this can also happen in the presence of intact neurometabolic coupling and - at least in vitro-no obvious restriction of glucose and oxygen supply (Figure 2). On the other hand, metabolic disturbances during frequently recurring seizures or in chronic epileptic tissue rather favor than limit the occurrence of hypersynchronous activity (Otáhal et al., 2014, and citations therein).

\section{SEIZURE ASSOCIATED ALTERATIONS IN ENERGY METABOLISM INTERMEDIATES AND pH}

Recurrent seizures represent an extraordinary metabolic burden, leading to increased tissue lactate and decreased phosphocreatine, glucose and glycogen content (Folbergrová et al., 2000). One plausible explanation for self-limitation of the hypersynchronous activity would be an exhaustion of the high energy phosphate and/or the glucose reserves. Neuronal metabolism is fueled almost exclusively by glucose as substrate, but the role of glucose availability in seizure development and termination is controversial. The glucose transporter GLUT1 plays an essential role in capillary to brain glucose transport and mutations in the SLC2A1 gene that encodes GLUT1 lead to deficiency of the transporter and cause several types of generalized epilepsy (Hildebrand et al., 2014). Epilepsy patients with diagnosed GLUT1 deficiency highly benefit from ketogenic diet. Severe hypoglycaemia by itself is known to induce seizures and moderate hypoglycemia decreased the threshold of seizure induction by fluorothyl in vivo (Kirchner et al., 2006). This could be brought about by the enhanced excitability as a consequence of altered Na-K-ATPase activity. Alternatively, an imbalance of excitatory and inhibitory neuron tonus has been also suggested, as the latter cells are more dependent on oxidative metabolism (Pumain et al., 2008). On the contrary, hypoglycaemia exerted anticonvulsant effects in vitro on low$\mathrm{Mg}^{2+}$ induced seizures (Kirchner et al., 2006). With respect to another immediate energy resource, phosphocreatine, it was shown that brain-type creatine kinase deficient transgenic mice were less prone to develop seizures under pentylenetetrazole. In these animals initial discharges developed into a depression, which suggests that an energy crisis might actually contribute to seizure termination (Streijger et al., 2010). However, the evidence for an energy crisis in terms of ATP depletion is rather limited in other animal models of epilepsy. ATP and high energy phosphate levels are kept close to normal even during recurrent seizures (status epilepticus) lasting for hours as was shown in an NMR study of kainate-induced status (Meric et al., 1994). By modeling seizure associated changes in energy metabolism intermediates and cerebral metabolic rate of oxygen consumption $\left(\mathrm{CMRO}_{2}\right)$ in a brain slice preparation 
A

\section{neurometabolic coupling}

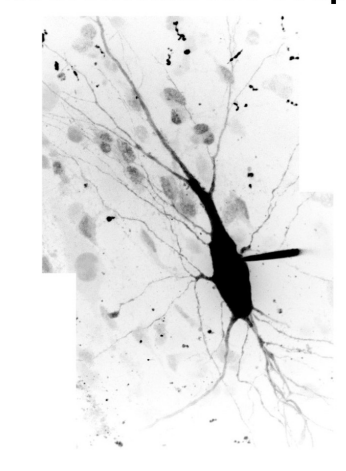

neurovascular coupling

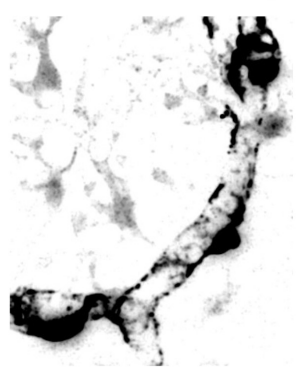

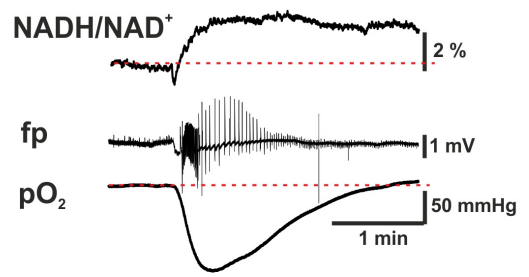

reactive oxygen species
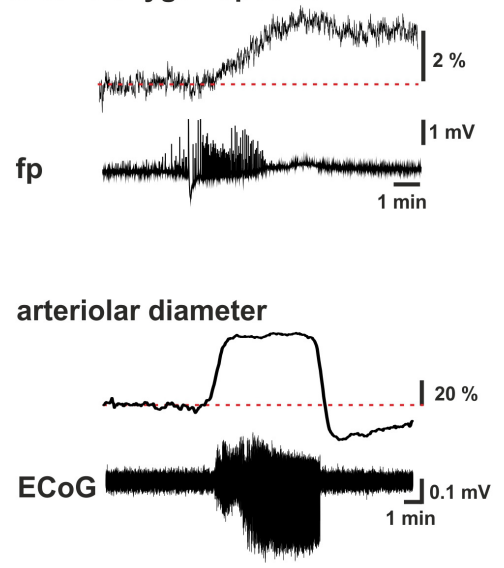

B

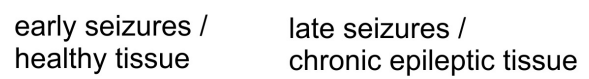

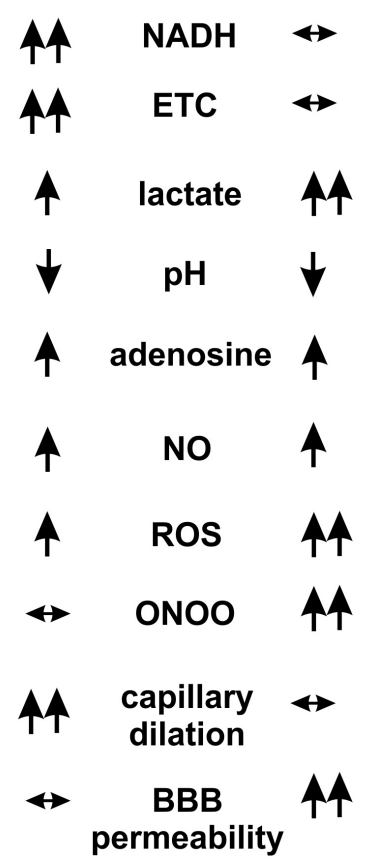

FIGURE 2 | Summary scheme of seizure-associated changes in cellular energy metabolism and cerebral blood. (A) Seizure-associated changes in transmembrane ion gradients ultimately activate neuronal energy metabolism in order to counterbalance the ATP-need of the ion pump activity. In brain slices kept under constant carbogen gassing conditions seizure-associated enhancement of respiration can be measured as a drop in $\mathrm{pO}_{2}$ whereas a shift in the fluorescence of $\mathrm{NADH}$ represents the metabolism-dependent redox shift of this electron carrier (fp: local field potential). Whereas the respiration slowly returns to the pre-seizure values following cessation of the activity, the reducing shift in the $\mathrm{NADH} / \mathrm{NAD}^{+}$ratio outlast the changes in respiration. This mismatch might favor the late enhancement of reactive oxygen species (ROS) formation, as represented here by the oxidation of the mitochondrially targeted ethidium derivative, MitoSox in the same preparation. Seizures are associated with reversible arteriolar and capillary vasodilation, the latter likely mediated by contractile pericytes, and a consequent overshooting $\mathrm{pO}_{2}$ response. (B) There are considerable differences in the seizure-associated neurometabolic and neurovascular responses between early and late events during status epilepticus, as well as in healthy and chronic epileptic tissue (arrows indicate the direction of the change of individual parameters). Seizure-associated overshooting $\mathrm{NADH}$ reduction eroded during recurrent seizures in vitro and it was almost absent in chronic epileptic tissue from epilepsy patients, due to the free radical dependent damage of mitochondrial dehydrogenases. On the other hand, mitochondrial injury might in turn enhance subsequent formation of reactive oxygen species (ROS) in a vicious cycle. Seizures resulted in lactate release both in control and chronic epileptic tissue samples, whereas in the latter even interictal lactate levels were increased likely reflecting altered expression pattern of monocarboxylate transporters and energy metabolism of glial cells. Seizure-associated enhancement of respiration and lactate release result in a metabolic acidosis, which - along with the enhanced adenosine levels- represents a strong anticonvulsant mechanisms even in chronic epileptic tissue. Despite the induction of massive CBF increase by seizures vascular responsiveness was found to be decreased following status epilepticus, and changes in pericytic reactivity are observable already few minutes after seizure onset. This could be brought by oxidative stress of these cells as described in the no reflow phenomenon after hypoxia-reperfusion. Although seizure-associated increase in nitric oxide (NO) formation contributes to the hyperemia, in the presence of superoxide NO is turned into peroxynitrite with deleterious consequences on microcirculation. Postictal hyporesponsiveness of the microvasculature has been speculated to underlie cognitive disturbances and epilepsia comorbidities, whereas damage of the blood-brain barrier (BBB), albumin leakage and the subsequent transformation of the nervous tissue were shown to be pro- epileptogenic. (hippocampal pyramidal cell and capillary pericytes are just for illustration purposes, some of the traces in A are adopted from Malinska et al., 2010).

Schoknecht and colleges showed that a fivefold increase in $\mathrm{CMRO}_{2}$ was able to compensate for the enhanced energy demand of seizures whereas the decrease in overall cytosolic ATP content remained relatively small (Schoknecht et al., 2017). Nevertheless, in certain metabolic compartments - such as the axonal/presynaptic domain of fast spiking interneurons larger local ATP consumption could be hypothesized (Hu et al., 2018).

In addition to the increased blood flow and the consequent increase in glucose supply, astrocytic glycogen reserves are also mobilized during seizures (Folbergrová et al., 2000). Astrocytes form an electrically and metabolically coupled network of cells (Boison and Steinhäuser, 2018), which is capable to transport glucose to the most active areas during seizure-like events in vitro (Rouach et al., 2008). Impairment of gap junctional coupling and connexin expression of astrocytes is often observed in chronic epileptic tissue (Bedner et al., 2015). Whether these changes contribute to the control of seizures remains controversial as both, pro- and anticonvulsant effects of the uncoupled network are possible, via impaired potassium, glutamate buffering and 
nutrient redistribution, respectively (Boison and Steinhäuser, 2018; and citations therein).

In addition to enhanced oxidative metabolism, surplus glucose can be turned into lactate by anaerob metabolism. Interstitial lactate accumulation during seizures is a general finding in patients, animals as well as in in vitro models of epilepsy (Calabrese et al., 1991; Meric et al., 1994; Doğan et al., 2017). In epilepsy patients interictal lactate levels were found to be elevated, suggesting altered energy metabolism and lactate turnover in general (Cavus et al., 2005). Although lactate is effectively removed into the bloodstream, it has been long speculated that lactate might serve as an alternative substrate for energy metabolism of neurons under conditions of increased demand. Despite the controversy on the validity of astrocyticneuronal lactate shuttle (ANLS) (Pellerin and Magistretti, 2012; Dienel, 2017), lactate seems to play a role in synaptic transmission and plasticity in the presence of ample glucose and might support energy demanding network oscillations in the gamma range (Galow et al., 2014; Nagase et al., 2014). Monocarboxylate transporters (MCT) mediate lactate uptake and release, depending on the transporter affinity and the concentration gradients, although lactate release via ion channels has been also described (Pierre and Pellerin, 2005; SoteloHitschfeld et al., 2015). MCT4 is the major MCT isoform present with particularly high density at the astrocytic endfeet enwrapping the cerebral microvasculature (Pierre and Pellerin, 2005), hinting that MCT4 facilitates the removal of lactate into the circulation. In addition to the perivascular endfeet, the high affinity MCT2 isoform is preferentially localized on post-synaptic structures (Bergersen et al., 2005; Bergersen, 2007) suggesting that this isoform might be responsible for the metabolic support of synaptic signaling (Galeffi et al., 2007; Nagase et al., 2014). The low affinity isoform MCT1 is expressed in astrocytes, oligodendrocytes and capillary endothelial cells and it is critically involved in oligodendrocyte development and maintenance of axonal functions (Lee et al., 2012).

We have recently shown that intrinsic lactate supports synaptic signaling in rat hippocampal slices and it contributes to energy demand of the restoration of transmembrane ion gradients (Angamo et al., 2016). Inhibition of the MCT2mediated lactate transport by $\alpha$-cyano- 4 -hydroxycinammic acid (4CIN) led to a decrease in postsynaptic action potential generation and this effect was dependent on the activation of $\mathrm{K}_{\mathrm{ATP}}$ channels, indicative of local energy shortage. Indeed, MCT inhibition reduced basal and stimulus-dependent $\mathrm{CMRO}_{2}$ and induced marked alterations in the redox state of mitochondrial $\mathrm{FADH}_{2}$ (Angamo et al., 2016). With respect to hypersynchronous activity we found a strong inhibition of interictal- and seizurelike events in presence of $4 \mathrm{CIN}$ in different in vitro models of epilepsy. Interestingly, while $\mathrm{K}_{\mathrm{ATP}}$ channels contributed to the suppression of synaptic activity, the anticonvulsant effect of MCT inhibitors could not be blocked by glibenclamide, which is in line with the assumption that seizure-associated overall increase in ATP consumption is counterbalanced by the enhanced oxidative metabolism (Schoknecht et al., 2017). The anticonvulsant effect of MCT inhibitors was present both, in brain slices from control rats and also in chronic epileptic tissue from epilepsy surgery. This suggests that lactate support of energy metabolism during seizures is a general phenomenon and it is not affected by the observed changes in MCT expression in chronic epileptic tissue (Lauritzen et al., 2012; Angamo et al., 2017). The anticonvulsant effect of lactate uptake inhibitors complements the study of Sada and colleges, demonstrating that inhibition of the lactate dehydrogenase (LDH) with a stiripentol analog suppressed seizures in the pilocarpine model in vivo (Sada et al., 2015).

The suppression of seizure-like activity by MCT inhibitors was not mediated by extracellular lactate accumulation and subsequent acidosis but rather by activation of adenosine receptors following adenosine release upon enhanced neuronal activity in the presence of substrate restriction. Application of the adenosine 1 (A1) receptor antagonist DPCPX could reverse completely the antiseizure effect of 4CIN (Angamo et al., 2017) indicating the critical role of these receptors in seizure termination. Indeed, endogenous adenosine is known to be released during seizures and A1 receptors are mainly responsible for the control of neuronal excitability by adenosine (Dunwiddie, 1980; Fedele et al., 2006; Lovatt et al., 2012). Microdialysis studies in patients with temporal lobe epilepsy have also shown that adenosine levels rise as a consequence of seizures and the subsequent seizure termination is mediated by the activation of A1 receptors (During and Spencer, 1992; Van Gompel et al., 2014). Al receptors are Gi/o protein coupled receptors which reduce the release of glutamate by inhibiting voltage-gated calcium channels (Kuroda, 1978; Mogul et al., 1993) and decrease postsynaptic excitability of neurons by enhancing G-protein coupled inwardly rectifying potassium conductances (Haas and Greene, 1984; Trussell and Jackson, 1987). Adenosine is thought to act as a neuromodulator involved in the homeostatic balance between inhibition and excitation, whereby A1 receptors may be responsible for reduced excitability and synaptic transmission subsequently resulting in a dampened network activity (Cunha, 2001; Dias et al., 2013). In fact, A1 receptors were found to decrease the power of gamma oscillations in hippocampal brain slices (Pietersen et al., 2009; Schulz et al., 2012). Activation of A1 receptors has in general a strong anticonvulsant efficacy in both rodent and human brain slices (Szybala et al., 2009; Klaft et al., 2012, 2016). A1 agonists were even capable to prevent the transition to status epilepticus-like recurrent discharges in vitro (Avsar and Empson, 2004) suggesting that status epilepticus may result from impaired adenosine receptor-dependent seizure termination mechanisms (Young and Dragunow, 1994; Kochanek et al., 2006; Hamil et al., 2012).

Notably, inhibiting glycolysis by application of 2DG is able to arrest seizures in different in vivo models (Stafstrom et al., 2008, 2009; Shao and Stafstrom, 2017). However, a more intricated set of effects is hinted by the findings that acute exposure to 2DG could either elevate or decrease the seizure threshold, depending on the epilepsy model $(6 \mathrm{~Hz}$ stimulation versus kainic acid, PTZ, electroshock and amygdala kindling induced seizures; Gasior et al., 2010), whereas chronic application of 2DG initiated epileptogenesis (Samokhina et al., 2017), likely mimicking the effect of mild hypoglycaemia. 
Thus, Gasior and colleges concluded that the proconvulsant action might be related to restriction of glucose uptake and subsequent hypoglycaemia while anticonvulsant effects could work via the inhibition of glycolysis. Under these conditions, glucose metabolism is shunted via the pentose phosphate cycle, which has been suggested to be anticonvulsant per se (Lian et al., 2007). Remarkably, in this study bypassing the block of the glycolytic pathway by the administration of extrinsic lactate abolished the anticonvulsant activity of 2DG in the pilocarpine model of epilepsy. This finding further reinforces the role of intrinsic lactate as possible energy resource during seizures and not a mere byproduct, which has to be removed into the bloodstream. Alterations in the expression pattern of different MCT subtypes in chronic epileptic tissue are in favor of lactate retention (Lauritzen et al., 2012), which might explain the increased interictal lactate levels, despite of the hypometabolism (Cavus et al., 2005).

The acute anticonvulsant effects of the ketogenic diet might be also related to the fact that ketone bodies represent a bypass of glycolysis, supporting the role of lactate in seizure control (Hartman and Stafstrom, 2013). However, mimicking the ketogenic diet in vitro failed to prevent the occurrence of seizures (Samoilova et al., 2010). On the long term both, chronic 2DG supply and ketogenic diet seem to work by changing gene expression and the whole machinery of energy metabolism (Bough and Rho, 2007). Similar long term changes might underlie the fact that chronic metabolic support by pyruvate administration can be actually anticonvulsant in three different epilepsy models (Popova et al., 2017). As these alterations are not expected to contribute to seizure termination under normal dietary conditions, the reader is referred to excellent recent reviews on this topic.

Although the effect of MCT inhibitors was not mediated by changes in $\mathrm{pH}$, the acidosis occurring during seizures is in turn capable to reduce neuronal excitability (Lux et al., 1986; Xiong et al., 2000; Wemmie et al., 2013) and by itself can exert strong anticonvulsant effects (Caspers and Speckmann, 1972). Extracellular acidosis emerges from the enhanced respiration resulting in $\mathrm{H}_{2} \mathrm{CO}_{3}$ formation in addition to the release of lactate (Mookerjee et al., 2015). Besides its intracellular effects (Wei et al., 2011) metabolic acidosis can alter excitability by many different ways (Sinning and Hübner, 2013), i.e., by activation of ASIC channels on interneurons (Ziemann et al., 2008) negative modulation of the $\mathrm{N}$-methyl-D-aspartate (NMDA) receptor currents (Tang et al., 1990), inhibition of presynaptic voltage gated $\mathrm{Ca}^{2+}$ currents (Wemmie et al., 2013) as well as facilitation of ecto-ATPases and increasing adenosine release (Dulla et al., 2005).

Nevertheless, intracellular acidosis could directly influence GABAergic transmission as the GABA receptor channel is permeable to $\mathrm{HCO}_{3}{ }^{-}$(Pavlov et al., 2013; Ruusuvuori and Kaila, 2014). Indeed, inhibitors of brain carbonic anhydrases, which actively control $\mathrm{pH}$ balance by catalyzing the interconversion of carbon dioxide to bicarbonate $\left(\mathrm{HCO}^{-}\right)$and a proton $\left(\mathrm{H}^{+}\right)$, possess anticonvulsant effects (Reiss and Oles, 1996; Mishra et al., 2018).
Thus, while manipulation of substrate availability and metabolic pathways could be pro and anticonvulsive, acidosis and adenosine represent two powerful and interdependent negative feedback mechanisms for intrinsic seizure termination by signalizing excessive metabolic activity before shortage of the substrates would appear (Dulla et al., 2005; Tolner et al., 2011).

\section{SEIZURE-ASSOCIATED CHANGES IN $\mathrm{CMRO}_{2}$ AND CEREBRAL BLOOD FLOW}

Besides the potentially catastrophic events such as disturbances in cerebral blood flow or phenomena like spreading depolarization (Dreier, 2011), seizures represent a metabolic burden which likely pushes brain energy metabolism to its limits. This assumption is supported by the finding that energy demanding physiologicaltype of network activity, such as carbachol induced lasting gamma oscillations in the brain slice preparation, result in a similar increase in $\mathrm{CMRO}_{2}$ as observed during seizure-like activity in the same tissue (Huchzermeyer et al., 2008; Kann et al., 2011). While the enhancement of $\mathrm{CMRO}_{2}$ is sufficient to keep transmembrane ion-gradients constant during gamma oscillations, seizure-like events result in massive changes in ion homeostasis (Huchzermeyer et al., 2013). Thus, it is tempting to speculate that ion transport capacity -and the corresponding ATP demand- is covered by the increase in the $\mathrm{CMRO}_{2}$ under physiological network activity. Any further increase in ion-fluxes exceeding pump capacity would result in altered transmembrane gradients, without further induction of $\mathrm{CMRO}_{2}$ increase.

Seizure-associated increases in $\mathrm{CMRO}_{2}$ in vivo can be calculated from the simultaneous determination of local tissue $\mathrm{pO}_{2}$ and cerebral blood flow (CBF, Gjedde, 2005; Thomsen et al., 2009) or by using fMRI as $\mathrm{CBF}, \mathrm{CMRO}_{2}$ and $\mathrm{CBV}$ are the dominant physiologic parameters that modulate the BOLD signal (Kida et al., 2000). However, these calculations has to take into account the local variability of the signals and the fact that their relation can be changed by the seizure itself. Thus under bicuculline induced lasting ictal activity a positive BOLD was observed in the cortex and a negative BOLD signal in the hippocampus, despite of the increase in $\mathrm{CBV}$ and neuronal activity in both regions, suggesting a local mismatch between $\mathrm{CMRO}_{2}$ and CBF (Schridde et al., 2008).

The brain slice preparation offers a simpler solution, because in the absence of blood flow, and permanent carbogen gassing $\left(95 \% \mathrm{O}_{2} 5 \% \mathrm{CO}_{2}\right)$ of the tissue, local $\mathrm{pO}_{2}$ depends solely on the rate of respiration and the diffusion distance from the surface (Liotta et al., 2012; Huchzermeyer et al., 2013). By recording basal and seizure-associated changes in $\mathrm{pO}_{2}$ and extracellular potassium/sodium concentration it was possible to calculate ATP consumption, ATP levels, $\mathrm{CMRO}_{2}$ and to predict the electron flow via the TCA enzymes and electron carrier nucleotides, $\mathrm{FADH}_{2}$ and NAD (Schoknecht et al., 2017). The transformation from interictal to seizure-like events was associated with a fivefold increase in oxygen consumption, whereas the corresponding increase in ATP demand was significantly higher, indicating that coupling ratio $\left(\mathrm{ATP} / \mathrm{O}_{2}\right)$ and thereby the efficiency of oxidative metabolism is improved during seizure-like events. Notably, at 
maximum $\mathrm{CMRO}_{2}$, tissue $\mathrm{pO}_{2}$ as well as the reducing equivalents for the ETC were not rate limiting for the energy metabolism, suggesting that shortage of these factors is not a necessary prerequisite for seizure termination (Foster et al., 2005; Ivanov et al., 2015). Although these data were obtained in vitro, the results on $\mathrm{CMRO}_{2}$ and $\mathrm{pO}_{2}$ distribution can be extrapolated to the in vivo situation by knowing the intercapillary distance and the seizure-associated changes in local cerebral blood flow response.

In general, based on the close relationship between neuronal activity and vascular response (i.e., neurovascular coupling), seizures induce reversible vasodilation and disproportionally high increases in the blood flow, resulting in an overshooting supply of oxygenated hemoglobin, underlying the seizureassociated BOLD response (Tyvaert et al., 2009; Thornton et al., 2010). The first hypotheses of functional hyperemia assumed that increased energy consumption by active neurons induce vasodilation directly by altering the concentration of extracellular potassium, oxygen, protons and different metabolites (Nilsson et al., 1978). Alternatively, neuronal activity-dependent increase of extracellular glutamate can induce the release of vasoactive substances such as NO leading to subsequent smooth muscle cell relaxation (Lauritzen, 2005; Busija et al., 2007). Astrocytes, the anatomical intermediaries between neurons and blood vessels, are important mediators of neurovascular coupling by releasing either vasodilator or vasoconstrictor agents in addition to potassium signaling at the astrocytic end-feet (Zonta et al., 2003; Filosa et al., 2006; Gordon et al., 2008; Petzold and Murthy, 2011; Filosa and Iddings, 2013). Ictal increases in parenchymal lactate concentration also contribute to the regulation of cerebral blood flow. In the presence of restricted oxygen availability and high astrocytic calcium concentrations astrocytic lactate release is maximized. The subsequent lactate accumulation attenuates transporter-mediated uptake of prostaglandin E2 (PGE2) from the extracellular space leading to subsequent vasodilation (Gordon et al., 2008). Thus, the vascular effect of lactate has to be kept in mind when considering the anticonvulsant effects of lactate uptake or glycolysis inhibitors under in vivo conditions. Finally, seizure-associated increases in extracellular adenosine have also vasodilatory effects by inhibiting constriction of arteriolar smooth muscle cells via adenosine receptors (Gordon et al., 2008).

The overshooting blood flow response to seizures led to the 'unorthodox' hypothesis that ictogenesis is actually a restorative process to increase supply in underperfused areas (Doman and Pelligra, 2003). Nevertheless, more recent results show that BOLD signal is preceded by a local $\mathrm{pO}_{2}$ dip and temporary reduction of the blood flow was documented in the tissue surrounding the epileptic focus as well as in the contralateral hemisphere (Zhao et al., 2011; Ma et al., 2013; Harris et al., 2014), indicating that the underperfusion per se is not an initiator of ictogenesis.

Status epilepticus and even a single seizure is associated with neuronal injury which in turn might favor secondary ictogenesis (Heinemann, 2004). The first clear proof of selective neuronal loss following status epilepticus appeared early in the 18th century, describing a sequence of cellular changes observed with Nissl staining in the brains of seven patients dying during the course of status epilepticus (Clark and Prout, 1903). The idea that ischemic processes could explain the cell loss in status epilepticus was developed about 100 years ago but questioned steadily based on the presence of massive hyperaemia and hyperoxygenation (Pfleger, 1880; Meldrum, 2002). Alternatively Pinard et al. (1984) suggested that not hypoxia but rather the release of endogenous substances and excitotoxic cascades mediate an excessive rise in $\left[\mathrm{Ca}^{2+}\right] \mathrm{i}$ resulting in cell death. Theoretically, a relative hypoperfusion of the tissue might occur also with intact neurovascular coupling if we presume that the diffusion-limited oxygen delivery can not keep up with a local increases in $\mathrm{CMRO}_{2}$. This kind of hypoperfusion might underlie the local negative BOLD signal indicating a mismatch between $\mathrm{CBF}$ and $\mathrm{CMRO}_{2}$ (Schridde et al., 2008). While such changes would remain undetected with the conventional doppler flowmetry (Geneslaw et al., 2011), doppler-based functional ultrasound imaging modality could reveal seizure-associated relative hypoperfusion at the microcircuitry level (Urban et al., 2017). Oxygen transport from the capillary in the tissue is driven by the oxygen gradient within the tissue. Thus an increase in $\mathrm{CMRO}_{2}$ would require an equal increase in the oxygen gradients. Taking into account that during high energy demand a significant part of the tissue exhibits $\mathrm{pO}_{2}$ below $50 \%$ compared to the capillary value (Schneider et al., 2017), the increase in capillary $\mathrm{pO}_{2}$ observed as a positive BOLD signal can still mean hypoxic $\mathrm{pO}_{2}$ at certain places within the brain parenchim. Such phenomenon was observed during spreading depolarization in the neocortex where monitoring the tissue redox potential revealed hypoperfused "islets" between capillaries (Takano et al., 2007). Similar hypoperfused areas might be present at the immediate vicinity of seizure focus, indicating altered blood distribution rather than disturbances of neurovascular coupling (Zhao et al., 2009). On the other hand, status epilepticus was shown to induce damage and to severely alter the neurovascular unit, including dysfunction of the blood-brain-barrier (BBB, Abbott and Friedman, 2012; Heinemann et al., 2012), which might also affect the functionality of neurovascular coupling and substrate supply during recurrent seizures. Thus interictal hypoperfusion is not a sole consequence of cell loss and impaired neuronal energy metabolism but it might also represent disturbances of neurovascular coupling at the microcirculation level (see next chapter).

\section{UNCOUPLING OF BLOOD FLOW AND ICTAL EVENTS AND POSTICTAL DISTURBANCES OF METABOLIC SUPPLY}

Neurovascular coupling necessitates information flow between neurons, astrocytes, endothelial cells and the contractile elements of the vasculature, i.e., the smooth muscle cells in arterioles and pericytes in capillaries (Petzold and Murthy, 2011; Hall et al., 2014). Disturbances in NVC has been associated with several pathologies, including stroke (Yemisci et al., 2009), hypertension (Dunn and Nelson, 2014), Alzheimer's disease 
(Rancillac et al., 2012), and subarachnoid hemorrhage (Piilgaard and Lauritzen, 2009). In epilepsy, alterations in the function of the neurovascular unit were found in epileptic tissue following status epilepticus leading to BBB impairment (Gorter et al., 2015; Bar-Klein et al., 2017). Following pilocarpineinduced status epilepticus heterogeneously distributed vascular alterations were observed within the cerebral cortex (Fabene et al., 2007). Superficial arteries and veins remained intact allowing for increased blood flow, whereas microvasculature showed a reduction of the diameter, resulting in an ischemic core in the deeper layers of the cortex. Moreover, neurovascular coupling was found to be deviate from the electrical activity and even impaired following seizures (Parfenova et al., 2005, 2012; Ma et al., 2013; Harris et al., 2014), thus raising the question whether inadequate perfusion and hypoxia may contribute to the pathophysiological changes in energy metabolism following status epilepticus. Indeed, fluorescence life-time measurement of $\mathrm{NADH}$ revealed metabolic impairment in bicuculline induced focal seizure activity in vivo likely due to inadequate blood supply (Yaseen et al., 2017).

With respect to microcirculation, gap junction-coupled contractile pericytes gained importance as the key executors of neurovascular coupling at the capillaries (Peppiatt et al., 2006; Hall et al., 2014; Mishra et al., 2016). Pericytic injury has been described to be accompanied by neurovascular dysfunction in various neurological disorders(for review see Winkler et al., 2011). Pericyte degeneration induced whitematter hypoxia and loss of myelin, (Montagne et al., 2018) and peroxynitrite-dependent pericytic dysfunction could completely disrupt passage of erythrocytes in capillaries as seen in the noreflow phenomenon following ischemia (Yemisci et al., 2009). On the other hand, Hall et al. (2014) found free radicalindependent pericytic dysfunction following oxygen glucose deprivation in brain slices. Similar to hypoxia-reperfusion, epileptic seizures are also associated with increased formation of oxygen and nitrogen centered free radicals, both in vivo (Folbergrová et al., 2012) and in vitro (Kovács et al., 2002, 2009). However, it is not known whether the formation of free radicals during status epilepticus would also influence pericyte function. Nevertheless, the redistribution of pericytes have been shown after status epilepticus (Milesi et al., 2014) and pericyte-mediated capillary vasospasm was observed in a genetic model of epilepsy and in kainic acid-treated animals following seizure onset (Leal-Campanario et al., 2017). Postictal hypoxia due to cyclooxygenase-2 activity-dependent vasoconstriction has been made responsible for the debilitating consequences of seizures (Farrell et al., 2016, 2017a). Theoretically, such changes in capillary perfusion would remain undetected with conventional methods of blood flow monitoring and could contribute to the development of local under-supply in case of subsequent seizures. Altogether, these studies highlight the importance of examining the time course and development of metabolic- and neurovascular-abnormalities associated with seizures. Besides the fact that capillaries are buried deep in the brain tissue and only accessible to multiphoton imaging or endomicroscopy, the difficulty with monitoring of pericytic regulation of capillary blood flow during seizures in vivo is that dilations of precapillary arteries/arterioles or changes in systemic blood pressure might influence the responses of pericytes (Fernández-Klett and Priller, 2015). Alternatively, the use of in vitro preparation have been suggested that combine the application of haemodynamic variables (such as flow and pressure) into parenchymal arterioles with the advantages of capillary imaging in brain slices (Kim and Filosa, 2012). In order to study capillary responses and BBB function in a controlled microenvironment we established a slice culture model of organotypic microvasculature. In this experimental setting, components of the neurovascular unit and BBB remain functional (Moser et al., 2003; Camenzind et al., 2010) and pericyte-derived contractile cells regulate capillary diameter in response to vasoactive substrates and increased intramural pressure (Kovács et al., 2011). Moreover, vascular remodeling takes place upon lasting epileptiform activity, mimicking seizure-associated disturbances in neurovascular unit (MorinBrureau et al., 2011). Investigating capillary vasomotility in this preparation could provide insights on the mechanisms of pericytic disturbances underlying neurovascular uncoupling.

\section{CONCLUDING REMARKS}

In conclusion, substantial evidence suggests that seizure termination can occur in the presence of intact neurometabolic coupling and overshooting neurovascular responses without immediate limitation on the metabolism. On the other hand, enhanced energy metabolism exerts a strong negative feedback on neuronal excitability, mostly via adenosine and $\mathrm{pH}$ changes. Free radical-dependent damage of mitochondrial enzymes and the subsequent disturbances in energy metabolism observed in chronic epileptic tissue were found to be rather proconvulsive (Figure 2). Manipulating substrate availability, preventing glycolysis, lactate uptake as well as enhancing pentose phosphate shunt might have both acute pro- or anticonvulsant effects, whereas chronic dietary changes can exert seizure control via epigenetic mechanisms. Thus targeting negative feedback mechanisms involved in metabolism dependent regulation of excitability as well as supporting cellular bioenergetics and protecting neurovascular coupling may represent promising therapeutic approaches in the treatment of epilepsy.

\section{AUTHOR CONTRIBUTIONS}

$\mathrm{RK}, \mathrm{NB}, \mathrm{OP}$, and ZG reviewed the bibliography and wrote the first draft of the manuscript. AF, SG, and JO added substantial comments after critical reading of the text.

\section{FUNDING}

This work was supported by EU grant EXC Neurocure (EXC 257) to AF and by the DFG grant Ko3814/1-1 to RK and by grant $18-07908$ S and $15-08565$ Sy CSF to JO. 


\section{REFERENCES}

Abbott, N. J., and Friedman, A. (2012). Overview and introduction: the blood-brain barrier in health and disease. Epilepsia 53(Suppl. 6), 1-6. doi: 10.1111/j.15281167.2012.03696.x

Ames, A. (2000). CNS energy metabolism as related to function. Brain Res. Brain Res. Rev. 34, 42-68. doi: 10.1016/S0165-0173(00)00038-2

Angamo, E. A., Rösner, J., Liotta, A., Kovács, R., and Heinemann, U. (2016) A neuronal lactate uptake inhibitor slows recovery of extracellular ion concentration changes in the hippocampal CA3 region by affecting energy metabolism. J. Neurophysiol. 116, 2420-2430. doi: 10.1152/jn.00327.2016

Angamo, E. A., ul Haq, R., Rösner, J., Gabriel, S., Gerevich, Z., Heinemann, U., et al. (2017). Contribution of intrinsic lactate to maintenance of seizure activity in neocortical slices from patients with temporal lobe epilepsy and in rat entorhinal cortex. Int. J. Mol. Sci. 18:1835. doi: 10.3390/ijms18091835

Avsar, E., and Empson, R. M. (2004). Adenosine acting via A1 receptors, controls the transition to status epilepticus-like behaviour in an in vitro model of epilepsy. Neuropharmacology 47, 427-437. doi: 10.1016/j.neuropharm.2004. 04.015

Bar-Klein, G., Lublinsky, S., Kamintsky, L., Noyman, I., Veksler, R., Dalipaj, H., et al. (2017). Imaging blood-brain barrier dysfunction as a biomarker for epileptogenesis. Brain 140, 1692-1705. doi: 10.1093/brain/awx073

Beamer, E., Otahal, J., Sills, G. J., and Thippeswamy, T. (2012). N(w) -propylL-arginine (L-NPA) reduces status epilepticus and early epileptogenic events in a mouse model of epilepsy: behavioural, EEG and immunohistochemical analyses. Eur. J. Neurosci. 36, 3194-3203. doi: 10.1111/j.1460-9568.2012. 08234.x

Bedner, P., Dupper, A., Huttmann, K., Muller, J., Herde, M. K., Dublin, P., et al. (2015). Astrocyte uncoupling as a cause of human temporal lobe epilepsy. Brain 138, 1208-1222. doi: 10.1093/brain/awv067

Ben-Ari, Y. (2001). Cell death and synaptic reorganizations produced by seizures. Epilepsia 42(Suppl. 3), 5-7. doi: 10.1046/j.1528-1157.2001.042suppl.3005.x

Bergersen, L. H. (2007). Is lactate food for neurons? Comparison of monocarboxylate transporter subtypes in brain and muscle. Neuroscience 145, 11-19. doi: 10.1016/j.neuroscience.2006.11.062

Bergersen, L. H., Magistretti, P. J., and Pellerin, L. (2005). Selective postsynaptic co-localization of MCT2 with AMPA receptor GluR2/3 subunits at excitatory synapses exhibiting AMPA receptor trafficking. Cereb. Cortex 15, 361-370. doi: $10.1093 /$ cercor/bhh138

Berndt, N., Kann, O., and Holzhütter, H. G. (2015). Physiology-based kinetic modeling of neuronal energy metabolism unravels the molecular basis of NAD(P)H fluorescence transients. J. Cereb. Blood Flow Metab. 35, 1494-1506. doi: $10.1038 / \mathrm{jcbfm} .2015 .70$

Boison, D., and Steinhäuser, C. (2018). Epilepsy and astrocyte energy metabolism. Glia 66, 1235-1243. doi: 10.1002/glia.23247

Bough, K. J., and Rho, J. M. (2007). Anticonvulsant mechanisms of the ketogenic diet. Epilepsia 48, 43-58. doi: 10.1111/j.1528-1167.2007.00915.x

Busija, D. W., Bari, F., Domoki, F., and Louis, T. (2007). Mechanisms involved in the cerebrovascular dilator effects of N-methyl-d-aspartate in cerebral cortex. Brain Res. Rev. 56, 89-100. doi: 10.1016/j.brainresrev.2007.05.011

Calabrese, V. P., Gruemer, H. D., James, K., Hranowsky, N., and DeLorenzo, R. J. (1991). Cerebrospinal fluid lactate levels and prognosis in status epilepticus. Epilepsia 32, 816-821. doi: 10.1111/j.1528-1157.1991.tb05538.x

Camenzind, R. S., Chip, S., and Gutmann, H. (2010). Preservation of transendothelial glucose transporter 1 and P-glycoprotein transporters in a cortical slice culture model of the blood-brain barrier. Neuroscience 170, 361371. doi: 10.1016/j.neuroscience.2010.06.073

Caspers, H., and Speckmann, E. J. (1972). Cerebral pO2, pCO2 and pH: changes during convulsive activity and their significance for spontaneous arrest of seizures. Epilepsia 13, 699-725. doi: 10.1111/j.1528-1157.1972.tb04403.x

Cavus, I., Kasoff, W. S., Cassaday, M. P., Jacob, R., Gueorguieva, R., Sherwin, R. S., et al. (2005). Extracellular metabolites in the cortex and hippocampus of epileptic patients. Ann. Neurol. 57, 226-235. doi: 10.1002/ana.20380

Cendes, F., Caramanos, Z., Andermann, F., Dubeau, F., and Arnold, D. L. (1997). Proton magnetic resonance spectroscopic imaging and magnetic resonance imaging volumetry in the lateralization of temporal lobe epilepsy: a series of 100 patients. Ann. Neurol. 42, 737-746. doi: 10.1002/ana.4104 20510
Clark, L. P., and Prout, T. P. (1903). Status epilepticus: a clinical and pathological study in epilepsy. Am. J. Psychiatry 60, 645-698. doi: 10.1176/ajp.61.1.81

Cunha, R. A. (2001). Adenosine as a neuromodulator and as a homeostatic regulator in the nervous system: different roles, different sources and different receptors. Neurochem. Int. 38, 107-125. doi: 10.1016/S0197-0186(00)00034-6

Denton, R. M. (2009). Regulation of mitochondrial dehydrogenases by calcium ions. Biochim. Biophys. Acta 1787, 1309-1316. doi: 10.1016/j.bbabio.2009.01. 005

Dias, R. B., Rombo, D. M., Ribeiro, J. A., Henley, J. M., and Sebastião, A. M. (2013). Adenosine: setting the stage for plasticity. Trends Neurosci. 36, 248-257. doi: $10.1016 /$ j.tins.2012.12.003

Dienel, G. A. (2017). Lack of appropriate stoichiometry: strong evidence against an energetically important astrocyte-neuron lactate shuttle in brain. J. Neurosci. Res. 95, 2103-2125. doi: 10.1002/jnr.24015

Doğan, E. A., Ünal, A., Ünal, A., and Erdoğan, C. (2017). Clinical utility of serum lactate levels for differential diagnosis of generalized tonic-clonic seizures from psychogenic nonepileptic seizures and syncope. Epilepsy Behav. 75, 13-17. doi: 10.1016/j.yebeh.2017.07.003

Doman, G., and Pelligra, R. (2003). Ictogenesis: the origin of seizures in humans. A new look at an old theory. Med. Hypotheses 60, 129-132. doi: 10.1016/S03069877(02)00348- 1

Dreier, J. P. (2011). The role of spreading depression, spreading depolarization and spreading ischemia in neurological disease. Nat. Med. 17, 439-447. doi: $10.1038 / \mathrm{nm} .2333$

Dulla, C. G., Dobelis, P., Pearson, T., Frenguelli, B. G., Staley, K. J., and Masino, S. A. (2005). Adenosine and ATP link PCO2 to cortical excitability via $\mathrm{pH}$. Neuron 48, 1011-1023. doi: 10.1016/j.neuron.2005.11.009

Dunn, K. M., and Nelson, M. T. (2014). Neurovascular signaling in the brain and the pathological consequences of hypertension. Am. J. Physiol. Heart Circ. Physiol. 306, H1-H14. doi: 10.1152/ajpheart.00364.2013

Dunwiddie, T. V. (1980). Endogenously released adenosine regulates excitability in the in vitro hippocampus. Epilepsia 21, 541-548. doi: 10.1111/j.1528-1157. 1980.tb04305.x

During, M. J., and Spencer, D. D. (1992). Adenosine: a potential mediator of seizure arrest and postictal refractoriness. Ann. Neurol. 32, 618-624. doi: 10.1002/ana. 410320504

Essig, C. F., and Flanary, H. G. (1966). The importance of the convulsion in occurrence and rate of development of electroconvulsive threshold elevation. Exp. Neurol. 14, 448-452. doi: 10.1016/0014-4886(66)90129-4

Fabene, P. F., Merigo, F., Galiè, M., Benati, D., Bernardi, P., Farace, P., et al. (2007). Pilocarpine-induced status epilepticus in rats involves ischemic and excitotoxic mechanisms. PLoS One 2:e1105. doi: 10.1371/journal.pone.0001105

Farrell, J. S., Colangeli, R., Wolff, M. D., Wall, A. K., Phillips, T. J., George, A., et al. (2017a). Postictal hypoperfusion/hypoxia provides the foundation for a unified theory of seizure-induced brain abnormalities and behavioral dysfunction. Epilepsia 58, 1493-1501. doi: 10.1111/epi.13827

Farrell, J. S., Gaxiola-Valdez, I., Wolff, M. D., David, L. S., Dika, H. I., Geeraert, B. L., et al. (2016). Postictal behavioural impairments are due to a severe prolonged hypoperfusion/hypoxia event that is COX-2 dependent. eLife 5:e19352. doi: 10.7554/eLife.19352

Farrell, J. S., Wolff, M. D., and Teskey, G. C. (2017b). Neurodegeneration and pathology in epilepsy: clinical and basic perspectives. Adv. Neurobiol. 15, 317-334. doi: 10.1007/978-3-319-57193-5_12

Fedele, D. E., Li, T., Lan, J. Q., Fredholm, B. B., and Boison, D. (2006). Adenosine A1 receptors are crucial in keeping an epileptic focus localized. Exp. Neurol. 200, 184-190. doi: 10.1016/j.expneurol.2006.02.133

Fernández-Klett, F., and Priller, J. (2015). Diverse functions of pericytes in cerebral blood flow regulation and ischemia. J. Cereb. Blood Flow Metab. 35, 883-887. doi: $10.1038 / \mathrm{jcbfm} .2015 .60$

Filosa, J. A., Bonev, A. D., Straub, S. V., Meredith, A. L., Wilkerson, M. K., Aldrich, R. W., et al. (2006). Local potassium signaling couples neuronal activity to vasodilation in the brain. Nat. Neurosci. 9, 1397-1403. doi: 10.1038/nn1779

Filosa, J. A., and Iddings, J. A. (2013). Astrocyte regulation of cerebral vascular tone. Am. J. Physiol. Heart Circ. Physiol. 305, H609-H619. doi: 10.1152/ajpheart. 00359.2013

Fisher, R. S., Acevedo, C., Arzimanoglou, A., Bogacz, A., Cross, J. H., Elger, C. E., et al. (2014). ILAE official report: a practical clinical definition of epilepsy. Epilepsia 55, 475-482. doi: 10.1111/epi.12550 
Fisher, R. S., van Emde Boas, W., Blume, W., Elger, C., Genton, P., Lee, P., et al. (2005). Epileptic seizures and epilepsy: definitions proposed by the international league against epilepsy (ILAE) and the International Bureau for Epilepsy (IBE). Epilepsia 46, 470-472. doi: 10.1111/j.0013-9580.2005.66104.x

Folbergrová, J., Haugvicová, R., and Mares, P. (2000). Behavioral and metabolic changes in immature rats during seizures induced by homocysteic acid: the protective effect of NMDA and non-NMDA receptor antagonists. Exp. Neurol. 161, 336-345. doi: 10.1006/exnr.1999.7264

Folbergrová, J., and Kunz, W. S. (2012). Mitochondrial dysfunction in epilepsy. Mitochondrion 12, 35-40. doi: 10.1016/j.mito.2011.04.004

Folbergrová, J., Otáhal, J., and Druga, R. (2012). Brain superoxide anion formation in immature rats during seizures: protection by selected compounds. Exp. Neurol. 233, 421-429. doi: 10.1016/j.expneurol.2011.11.009

Foster, K. A., Beaver, C. J., and Turner, D. A. (2005). Interaction between tissue oxygen tension and NADH imaging during synaptic stimulation and hypoxia in rat hippocampal slices. Neuroscience 132, 645-657. doi: 10.1016/j.neuroscience. 2005.01.040

Frantseva, M. V., Velazquez, J. L., Hwang, P. A., and Carlen, P. L. (2000). Free radical production correlates with cell death in an in vitro model of epilepsy. Eur. J. Neurosci. 12, 1431-1439. doi: 10.1046/j.1460-9568.2000.00016.x

Galeffi, F., Foster, K. A., Sadgrove, M. P., Beaver, C. J., and Turner, D. A. (2007). Lactate uptake contributes to the $\mathrm{NAD}(\mathrm{P}) \mathrm{H}$ biphasic response and tissue oxygen response during synaptic stimulation in area CA1 of rat hippocampal slices. J. Neurochem. 103, 2449-2461. doi: 10.1111/j.1471-4159.2007.04939.x

Galow, L. V., Schneider, J., Lewen, A., Ta, T. T., Papageorgiou, I. E., and Kann, O. (2014). Energy substrates that fuel fast neuronal network oscillations. Front. Neurosci. 5:398. doi: 10.3389/fnins.2014.00398

Gasior, M., Yankura, J., Hartman, A. L., French, A., and Rogawski, M. A. (2010). Anticonvulsant and proconvulsant actions of 2-deoxyD-glucose. Epilepsia 51, 1385-1394. doi: 10.1111/j.1528-1167.2010. 02593.x

Gellerich, F. N., Gizatullina, Z., Trumbekaite, S., Korzeniewski, B., Gaynutdinov, T., Seppet, E., et al. (2012). Cytosolic Ca2 + regulates the energization of isolated brain mitochondria by formation of pyruvate through the malate-aspartate shuttle. Biochem. J. 443, 747-755. doi: 10.1042/BJ20110765

Geneslaw, A. S., Zhao, M., Ma, H., and Schwartz, T. H. (2011). Tissue hypoxia correlates with intensity of interictal spikes. J. Cereb. Blood Flow Metab. 31, 1394-1402. doi: 10.1038/jcbfm.2011.16

Gjedde, A. (2005). "The pathways of oxygen in brain I," in Oxygen Transport to Tissue XXVI. Advances in Experimental Medicine and Biology, Vol. 566, eds P. Okunieff, J. Williams, and Y. Chen (Boston, MA: Springer).

Gordon, G. R., Choi, H. B., Rungta, R. L., Ellis-Davies, G. C., and MacVicar, B. A. (2008). Brain metabolism dictates the polarity of astrocyte control over arterioles. Nature 456, 745-749. doi: 10.1038/nature07525

Gorter, J. A., van Vliet, E. A., and Aronica, E. (2015). Status epilepticus, bloodbrain barrier disruption, inflammation, and epileptogenesis. Epilepsy Behav. 49, 13-16. doi: 10.1016/j.yebeh.2015.04.047

Guillon, B., Duncan, R., Biraben, A., Bernard, A. M., Vignal, J. P., and Chauvel, P. (1998). Correlation between interictal regional cerebral blood flow and depthrecorded interictal spiking in temporal lobe epilepsy. Epilepsia 39, 67-76. doi: 10.1111/j.1528-1157.1998.tb01276.x

Haas, H. L., and Greene, R. W. (1984). Adenosine enhances afterhyperpolarization and accommodation in hippocampal pyramidal cells. Pflugers Arch. 402, 244247. doi: 10.1007/BF00585506

Hall, C. N., Klein-Flügge, M. C., Howarth, C., and Attwell, D. (2012). Oxidative phosphorylation, not glycolysis, powers presynaptic and postsynaptic mechanisms underlying brain information processing. J. Neurosci. 32, 89408951. doi: 10.1523/JNEUROSCI.0026-12.2012

Hall, C. N., Reynell, C., Gesslein, B., Hamilton, N. B., Mishra, A., Sutherland, B. A., et al. (2014). Capillary pericytes regulate cerebral blood flow in health and disease. Nature 508, 55-60. doi: 10.1038/nature13165

Hamil, N. E., Cock, H. R., and Walker, M. C. (2012). Acute down-regulation of adenosine $\mathrm{A}(1)$ receptor activity in status epilepticus. Epilepsia 53, 177-188. doi: 10.1111/j.1528-1167.2011.03340.x

Harris, S., Boorman, L., Bruyns-Haylett, M., Kennerley, A., Ma, H., Zhao, M., et al. (2014). Contralateral dissociation between neural activity and cerebral blood volume during recurrent acute focal neocortical seizures. Epilepsia 55, 1423-1430. doi: 10.1111/epi.12726
Hartman, A. L., and Stafstrom, C. E. (2013). Harnessing the power of metabolism for seizure prevention: focus on dietary treatments. Epilepsy Behav. 26, 266-272. doi: 10.1016/j.yebeh.2012.09.019

Heinemann, U. (2004). Basic mechanisms of partial epilepsies. Curr. Opin. Neurol. 17, 155-159. doi: 10.1097/00019052-200404000-00012

Heinemann, U., Buchheim, K., Gabriel, S., Kann, O., Kovács, R., and Schuchmann, S. (2002). Coupling of electrical and metabolic activity during epileptiform discharges. Epilepsia 43(Suppl. 5), 168-173. doi: 10.1046/j.15281157.43.s.5.15.x

Heinemann, U., Kaufer, D., and Friedman, A. (2012). ). Blood-brain barrier dysfunction, TGF $\beta$ signaling, and astrocyte dysfunction in epilepsy. Glia 60, 1251-1257. doi: 10.1002/glia.22311

Hetherington, H., Kuzniecky, R., Pan, J., Mason, G., Morawetz, R., Harris, C., et al. (1995). Proton nuclear magnetic resonance spectroscopic imaging of human temporal lobe epilepsy at 4.1 T. Ann. Neurol. 38, 396-404. doi: 10.1002/ana. 410380309

Hildebrand, M. S., Damiano, J. A., Mullen, S. A., Bellows, S. T., Oliver, K. L., Dahl, H. H., et al. (2014). Glucose metabolism transporters and epilepsy: only GLUT1 has an established role. Epilepsia 55, e18-e21. doi: 10.1111/epi. 12519

Hong, S. B., Han, H. J., Roh, S. Y., Seo, D. W., Kim, S. E., and Kim, M. H. (2002). Hypometabolism and interictal spikes during positron emission tomography scanning in temporal lobe epilepsy. Eur. Neurol. 48, 65-70. doi: 10.1159/ 000062985

Hu, H., Roth, F. C., Vandael, D., and Jonas, P. (2018). Complementary tuning of $\mathrm{Na}+$ and $\mathrm{K}+$ channel gating underlies fast and energy-efficient action potentials in GABAergic interneuron axons. Neuron 98, 156.e5-165.e6. doi: 10.1016/j.neuron.2018.02.024

Huchzermeyer, C., Albus, K., Gabriel, H. J., Otáhal, J., Taubenberger, N., Heinemann, U., et al. (2008). Gamma oscillations and spontaneous network activity in the hippocampus are highly sensitive to decreases in pO2 and concomitant changes in mitochondrial redox state. J. Neurosci. 28, 1153-1162. doi: 10.1523/JNEUROSCI.4105-07.2008

Huchzermeyer, C., Berndt, N., Holzhütter, H. G., and Kann, O. (2013). Oxygen consumption rates during three different neuronal activity states in the hippocampal CA3 network. J. Cereb. Blood Flow Metab. 33, 263-271. doi: 10. 1038/jcbfm.2012.165

Ingvar, M. (1986). Cerebral blood flow and metabolic rate during seizures. Relationship to epileptic brain damage. Ann. N. Y. Acad. Sci. 462, 194-206. doi: 10.1111/j.1749-6632.1986.tb51254.x

Ivanov, A. I., Bernard, C., and Turner, D. A. (2015). Metabolic responses differentiate between interictal, ictal and persistent epileptiform activity in intact, immature hippocampus in vitro. Neurobiol. Dis. 75, 1-14. doi: 10.1016/ j.nbd.2014.12.013

Kang, H. C., Lee, Y. M., and Kim, H. D. (2013). Mitochondrial disease and epilepsy. Brain Dev. 35, 757-761. doi: 10.1016/j.braindev.2013.01.006

Kann, O., Huchzermeyer, C., Kovács, R., Wirtz, S., and Schuelke, M. (2011). Gamma oscillations in the hippocampus require high complex I gene expression and strong functional performance of mitochondria. Brain 134(Pt 2), 345-358. doi: 10.1093/brain/awq333

Kann, O., Kovács, R., Njunting, M., Behrens, C. J., Otáhal, J., Lehmann, T. N., et al. (2005). Metabolic dysfunction during neuronal activation in the ex vivo hippocampus from chronic epileptic rats and humans. Brain 128(Pt 10), 23962407. doi: 10.1093/brain/awh568

Kannurpatti, S. S. (2017). Mitochondrial calcium homeostasis: implications for neurovascular and neurometabolic coupling. J. Cereb. Blood Flow Metab. 37, 381-395. doi: 10.1177/0271678X16680637

Kasischke, K. A., Vishwasrao, H. D., Fisher, P. J., Zipfel, W. R., and Webb, W. W. (2004). Neural activity triggers neuronal oxidative metabolism followed by astrocytic glycolysis. Science 2, 99-103. doi: 10.1126/science. 1096485

Kida, I., Kennan, R. P., Rothman, D. L., Behar, K. L., and Hyder, F. (2000). Highresolution $\mathrm{CMR}(\mathrm{O} 2)$ mapping in rat cortex: a multiparametric approach to calibration of BOLD image contrast at 7 Tesla. J. Cereb. Blood Flow Metab. 20, 847-860. doi: 10.1097/00004647-200005000-00012

Kim, K. J., and Filosa, J. A. (2012). Advanced in vitro approach to study neurovascular coupling mechanisms in the brain microcirculation. J. Physiol. 590, 1757-1770. doi: 10.1113/jphysiol.2011.222778 
Kirchner, A., Velísková, J., and Velísek, L. (2006). Differential effects of low glucose concentrations on seizures and epileptiform activity in vivo and in vitro. Eur. J. Neurosci. 23, 1512-1522. doi: 10.1111/j.1460-9568.2006.04665.x

Klaft, Z. J., Hollnagel, J. O., Salar, S., Calişkan, G., Schulz, S. B., Schneider, U. C., et al. (2016). Adenosine A1 receptor-mediated suppression of carbamazepineresistant seizure-like events in human neocortical slices. Epilepsia 57, 746-756. doi: 10.1111/epi.13360

Klaft, Z. J., Schulz, S. B., Maslarova, A., Gabriel, S., Heinemann, U., and Gerevich, Z. (2012). Extracellular ATP differentially affects epileptiform activity via purinergic $\mathrm{P} 2 \mathrm{X} 7$ and adenosine $\mathrm{A} 1$ receptors in naive and chronic epileptic rats. Epilepsia 53, 1978-1986. doi: 10.1111/j.1528-1167.2012.03724.x

Kochanek, P. M., Vagni, V. A., Janesko, K. L., Washington, C. B., Crumrine, P. K., Garman, R. H., et al. (2006). Adenosine Al receptor knockout mice develop lethal status epilepticus after experimental traumatic brain injury. J. Cereb. Blood Flow Metab. 26, 565-575. doi: 10.1038/sj.jcbfm.9600218

Kovac, S., Domijan, A. M., Walker, M. C., and Abramov, A. Y. (2012). Prolonged seizure activity impairs mitochondrial bioenergetics and induces cell death. J. Cell Sci. 125(Pt 7), 1796-1806. doi: 10.1242/jcs.099176

Kovács, R., and Heinemann, U. (2014). Models in research of pharmacoresistant epilepsy: present and future in development of antiepileptic drugs. Curr. Med. Chem. 21, 689-703. doi: 10.2174/0929867320666131119152613

Kovács, R., Kardos, J., Heinemann, U., and Kann, O. (2005). Mitochondrial calcium ion and membrane potential transients follow the pattern of epileptiform discharges in hippocampal slice cultures. J. Neurosci. 25, 4260-4269. doi: 10. 1523/JNEUROSCI.4000-04.2005

Kovács, R., Papageorgiou, I., and Heinemann, U. (2011). Slice cultures as a model to study neurovascular coupling and blood brain barrier in vitro. Cardiovasc. Psychiatry Neurol. 2011:646958. doi: 10.1155/2011/646958

Kovács, R., Rabanus, A., Otáhal, J., Patzak, A., Kardos, J., Albus, K., et al. (2009). Endogenous nitric oxide is a key promoting factor for initiation of seizure-like events in hippocampal and entorhinal cortex slices. J. Neurosci. 29, 8565-8577. doi: 10.1523/JNEUROSCI.5698-08.2009

Kovács, R., Schuchmann, S., Gabriel, S., Kann, O., Kardos, J., and Heinemann, U. (2002). Free radical-mediated cell damage after experimental status epilepticus in hippocampal slice cultures. J. Neurophysiol. 88, 2909-2918. doi: 10.1152/jn. 00149.2002

Kovács, R., Schuchmann, S., Gabriel, S., Kardos, J., and Heinemann, U. (2001). $\mathrm{Ca} 2+$ signalling and changes of mitochondrial function during low-Mg2 + induced epileptiform activity in organotypic hippocampal slice cultures. Eur. J. Neurosci. 13, 1311-1319. doi: 10.1046/j.0953-816x.2001.01505.x

Kunz, W. S., Kudin, A. P., Vielhaber, S., Blümcke, I., Zuschratter, W., Schramm, J., et al. (2000). Mitochondrial complex I deficiency in the epileptic focus of patients with temporal lobe epilepsy. Ann. Neurol. 48, 766-773. doi: 10.1002/ 1531-8249(200011)48:5<766::AID-ANA10>3.0.CO;2-M

Kuroda, Y. (1978). Physiological roles of adenosine derivatives which are released during neurotransmission in mammalian brain. J. Physiol. 74, 463-470.

Lauritzen, F., Heuser, K., de Lanerolle, N. C., Lee, T. S., Spencer, D. D., Kim, J. H., et al. (2012). Redistribution of monocarboxylate transporter 2 on the surface of astrocytes in the human epileptogenic hippocampus. Glia 60, 1172-1181. doi: 10.1002/glia.22344

Lauritzen, M. (2005). Reading vascular changes in brain imaging: is dendritic calcium the key? Nat. Rev. Neurosci. 6, 77-85. doi: 10.1038/nrn1589

Leal-Campanario, R., Alarcon-Martinez, L., Rieiro, H., Martinez-Conde, S., Alarcon-Martinez, T., Zhao, X., et al. (2017). Abnormal capillary vasodynamics contribute to ictal neurodegeneration in epilepsy. Sci. Rep. 2017:43276. doi: $10.1038 /$ srep43276

Ledo, A., Barbosa, R., Cadenas, E., and Laranjinha, J. (2010). Dynamic and interacting profiles of * $\mathrm{NO}$ and $\mathrm{O} 2$ in rat hippocampal slices. Free Radic. Biol. Med. 48, 1044-1050. doi: 10.1016/j.freeradbiomed.2010.01.024

Lee, Y., Morrison, B. M., Li, Y., Lengacher, S., Farah, M. H., Hoffman, P. N., et al. (2012). Oligodendroglia metabolically support axons and contribute to neurodegeneration. Nature 487, 443-448. doi: 10.1038/nature 11314

Lian, X. Y., Khan, F. A., and Stringer, J. L. (2007). Fructose-1,6-bisphosphate has anticonvulsant activity in models of acute seizures in adult rats. J. Neurosci. 27, 12007-12011. doi: 10.1523/JNEUROSCI.3163-07.2007

Liotta, A., Rösner, J., Huchzermeyer, C., Wojtowicz, A., Kann, O., Schmitz, D., et al. (2012). Energy demand of synaptic transmission at the hippocampal
Schaffer-collateral synapse. J. Cereb. Blood Flow Metab. 32, 2076-2083. doi: $10.1038 /$ jcbfm. 2012.116

Löscher, W., and Köhling, R. (2010). Functional, metabolic, and synaptic changes after seizures as potential targets for antiepileptic therapy. Epilepsy Behav. 19, 105-113. doi: 10.1016/j.yebeh.2010.06.035

Lovatt, D., Xu, Q., Liu, W., Takano, T., Smith, N. A., Schnermann, J., et al. (2012). Neuronal adenosine release, and not astrocytic ATP release, mediates feedback inhibition of excitatory activity. Proc. Natl. Acad. Sci. U.S.A. 109, 6265-6270. doi: 10.1073/pnas.1120997109

Lux, H. D., Heinemann, U., and Dietzel, I. (1986). Ionic changes and alterations in the size of the extracellular space during epileptic activity. Adv. Neurol. 44, 619-639.

Ma, H., Zhao, M., and Schwartz, T. H. (2013). Dynamic neurovascular coupling and uncoupling during ictal onset, propagation, and termination revealed by simultaneous in vivo optical imaging of neural activity and local blood volume. Cereb. Cortex 23, 885-899. doi: 10.1093/cercor/bhs079

Malinska, D., Kulawiak, B., Kudin, A. P., Kovacs, R., Huchzermeyer, C., Kann, O., et al. (2010). Complex III-dependent superoxide production of brain mitochondria contributes to seizure-related ROS formation. Biochim. Biophys. Acta 1797, 1163-1170. doi: 10.1016/j.bbabio.2010.03.001

McCormack, J. G., Halestrap, A. P., and Denton, R. M. (1990). Role of calcium ions in regulation of mammalian intramitochondrial metabolism. Physiol. Rev. 70, 391-425. doi: 10.1152/physrev.1990.70.2.391

Meldrum, B. S. (2002). Concept of activity-induced cell death in epilepsy: historical and contemporary perspectives. Prog. Brain Res. 135, 3-11. doi: 10.1016/S00796123(02)35003-9

Meric, P., Barrere, B., Peres, M., Gillet, B., Berenger, G., Beloeil, J. C., et al. (1994). Effects of kainate-induced seizures on cerebral metabolism: a combined $1 \mathrm{H}$ and 31P NMR study in rat. Brain Res. 638, 53-60. doi: 10.1016/0006-8993(94) 90632-7

Milesi, S., Boussadia, B., Plaud, C., Catteau, M., Rousset, M. C., De Bock, F., et al. (2014). Redistribution of PDGFR $\beta$ cells and NG2DsRed pericytes at the cerebrovasculature after status epilepticus. Neurobiol. Dis. 71, 151-158. doi: 10.1016/j.nbd.2014.07.010

Mishra, A., Reynolds, J. P., Chen, Y., Gourine, A. V., Rusakov, D. A., and Attwell, D. (2016). Astrocytes mediate neurovascular signaling to capillary pericytes but not to arterioles. Nat. Neurosci. 19, 1619-1627. doi: 10.1038/nn.4428

Mishra, C. B., Kumari, S., Angeli, A., Bua, S., Tiwari, M., and Supuran, C. T. (2018). Discovery of benzenesulfonamide derivatives as carbonic anhydrase inhibitors with effective anticonvulsant action: design, synthesis, and pharmacological evaluation. J. Med. Chem. 61, 3151-3165. doi: 10.1021/acs.jmedchem.8b00208

Mogul, D. J., Adams, M. E., and Fox, A. P. (1993). Differential activation of adenosine receptors decreases N-type but potentiates P-type Ca2 + current in hippocampal CA3 neurons. Neuron 10, 327-334. doi: 10.1016/0896-6273(93) 90322-I

Montagne, A., Nikolakopoulou, A. M., Zhao, Z., Sagare, A. P., Si, G., Lazic, D., et al. (2018). Pericyte degeneration causes white matter dysfunction in the mouse central nervous system. Nat. Med. 24, 326-337. doi: 10.1038/nm.4482

Mookerjee, S. A., Goncalves, R. L. S., Gerencser, A. A., Nicholls, D. G., and Brand, M. D. (2015). The contributions of respiration and glycolysis to extracellular acid production. Biochim. Biophys. Acta 1847, 171-181. doi: 10.1016/j.bbabio. 2014.10.005

Morin-Brureau, M., Lebrun, A., Rousset, M. C., Fagni, L., Bockaert, J., de Bock, F., et al. (2011). Epileptiform activity induces vascular remodeling and zonula occludens 1 downregulation in organotypic hippocampal cultures: role of VEGF signaling pathways. J. Neurosci. 31, 10677-10688. doi: 10.1523/ JNEUROSCI.5692-10.2011

Moser, K. V., Schmidt-Kastner, R., Hinterhuber, H., and Humpel, C. (2003). Brain capillaries and cholinergic neurons persist in organotypic brain slices in the absence of blood flow. Eur. J. Neurosci. 18, 85-94. doi: 10.1046/j.1460-9568. 2003.02728.x

Nagase, M., Takahashi, Y., Watabe, A. M., Kubo, Y., and Kato, F. (2014). On-site energy supply at synapses through monocarboxylate transporters maintains excitatory synaptic transmission. J. Neurosci. 34, 2605-2617. doi: 10.1523/ JNEUROSCI.4687-12.2014

Nicholls, D. G. (2017). Brain mitochondrial calcium transport: origins of the setpoint concept and its application to physiology and pathology. Neurochem. Int. 109, 5-12. doi: 10.1016/j.neuint.2016.12.018 
Nilsson, B., Rehncrona, S., and Siesjö, B. K. (1978). Coupling of cerebral metabolism and blood flow in epileptic seizures, hypoxia and hypoglycaemia. Ciba Found. Symp. 56, 199-218.

Otáhal, J., Folbergrová, J., Kovacs, R., Kunz, W. S., and Maggio, N. (2014). Epileptic focus and alteration of metabolism. Int. Rev. Neurobiol. 114, 209-243. doi: 10.1016/B978-0-12-418693-4.00009-1

Parfenova, H., Carratu, P., Tcheranova, D., Fedinec, A., Pourcyrous, M., and Leffler, C. W. (2005). Epileptic seizures cause extended postictal cerebral vascular dysfunction that is prevented by HO-1 overexpression. Am. J. Physiol. Heart Circ. Physiol. 288, H2843-H2850. doi: 10.1152/ajpheart.01274.2004

Parfenova, H., Leffler, C. W., Basuroy, S., Liu, J., and Fedinec, A. L. (2012). Antioxidant roles of heme oxygenase, carbon monoxide, and bilirubin in cerebral circulation during seizures. J. Cereb. Blood Flow Metab. 32, 1024-1034. doi: $10.1038 /$ jcbfm.2012.13

Pavlov, I., Kaila, K., Kullmann, D. M., and Miles, R. (2013). Cortical inhibition, $\mathrm{pH}$ and cell excitability in epilepsy: what are optimal targets for antiepileptic interventions? J. Physiol. 591, 765-774. doi: 10.1113/jphysiol.2012.237958

Pellerin, L., and Magistretti, P. J. (2012). Sweet sixteen for ANLS. J. Cereb. Blood Flow Metab. 32, 1152-1166. doi: 10.1038/jcbfm.2011

Peppiatt, C. M., Howarth, C., Mobbs, P., and Attwell, D. (2006). Bidirectional control of CNS capillary diameter by pericytes. Nature 443, 700-704. doi: 10 . 1038/nature05193

Petzold, G. C., and Murthy, V. N. (2011). Role of astrocytes in neurovascular coupling. Neuron 71, 782-797. doi: 10.1016/j.neuron.2011.08.009

Pfleger, L. (1880). Beobachtungen uber schrumpfung und skierose des ammonshorns bei epilepsie. Allg. Z. Psychiatr. 36, 359-365.

Pierre, K., and Pellerin, L. (2005). Monocarboxylate transporters in the central nervous system: distribution, regulation and function. J. Neurochem. 94, 1-14. doi: $10.1111 / j .1471-4159.2005 .03168 . x$

Pietersen, A. N., Lancaster, D. M., Patel, N., Hamilton, J. B., and Vreugdenhil, M. (2009). Modulation of gamma oscillations by endogenous adenosine through $\mathrm{A} 1$ and A2A receptors in the mouse hippocampus. Neuropharmacology 56, 481-492. doi: 10.1016/j.neuropharm.2008.10.001

Piilgaard, H., and Lauritzen, M. (2009). Persistent increase in oxygen consumption and impaired neurovascular coupling after spreading depression in rat neocortex. J. Cereb. Blood Flow Metab. 29, 1517-1527. doi: 10.1038/jcbfm.2009. 73

Pinard, E., Tremblay, E., Ben-Ari, Y., and Seylaz, J. (1984). Blood flow compensates oxygen demand in the vulnerable CA3 region of the hippocampus during kainate-induced seizures. Neuroscience 13, 1039-1049. doi: 10.1016/0306$4522(84) 90287-2$

Popova, I., Malkov, A., Ivanov, A. I., Samokhina, E., Buldakova, S., Gubkina, O., et al. (2017). Metabolic correction by pyruvate halts acquired epilepsy in multiple rodent models. Neurobiol. Dis. 106, 244-254. doi: 10.1016/j.nbd.2017. 07.012

Pumain, R., Ahmed, M. S., Kurcewicz, I., Trottier, S., Louvel, J., Turak, B., et al. (2008). Lability of GABAA receptor function in human partial epilepsy: possible relationship to hypometabolism. Epilepsia 49(Suppl. 8), 87-90. doi: 10.1111/j. 1528-1167.2008.01845.x

Rancillac, A., Geoffroy, H., and Rossier, J. (2012). Impaired neurovascular coupling in the APPxPS1 mouse model of Alzheimer's disease. Curr. Alzheimer Res. 9, 1221-1230. doi: 10.2174/156720512804142859

Reiss, W. G., and Oles, K. S. (1996). Acetazolamide in the treatment of seizures. Ann. Pharmacother. 30, 514-519. doi: 10.1177/1060028096030 00515

Rouach, N., Koulakoff, A., Abudara, V., Willecke, K., and Giaume, C. (2008). Astroglial metabolic networks sustain hippocampal synaptic transmission. Science 322, 1551-1555. doi: 10.1126/science.1164022

Rowley, S., and Patel, M. (2013). Mitochondrial involvement and oxidative stress in temporal lobe epilepsy. Free Radic. Biol. Med. 62, 121-131. doi: 10.1016/j. freeradbiomed.2013.02.002

Rueda, C. B., Llorente-Folch, I., Amigo, I., Contreras, L., González-Sánchez, P., Martínez-Valero, P., et al. (2014). Ca $(2+)$ regulation of mitochondrial function in neurons. Biochim. Biophys. Acta 1837, 1617-1624. doi: 10.1016/j.bbabio. 2014.04.010

Ruusuvuori, E., and Kaila, K. (2014). Carbonic anhydrases and brain $\mathrm{pH}$ in the control of neuronal excitability. Subcell Biochem. 75, 271-290. doi: 10.1007/97894-007-7359-2_14
Sada, N., Lee, S., Katsu, T., Otsuki, T., and Inoue, T. (2015). Epilepsy treatment. Targeting LDH enzymes with a stiripentol analog to treat epilepsy. Science 347, 1362-1367. doi: 10.1126/science.aaa1299

Samoilova, M., Weisspapir, M., Abdelmalik, P., Velumian, A. A., and Carlen, P. L. (2010). Chronic in vitro ketosis is neuroprotective but not anti-convulsant. J. Neurochem. 113, 826-835. doi: 10.1111/j.1471-4159.2010.06645.x

Samokhina, E., Popova, I., Malkov, A., Ivanov, A. I., Papadia, D., Osypov, A., et al. (2017). Chronic inhibition of brain glycolysis initiates epileptogenesis. J. Neurosci. Res. 95, 2195-2206. doi: 10.1002/jnr.24019

Schneider, J., Berndt, N., Papageorgiou, I. E., Maurer, J., Bulik, S., Both, M., et al. (2017). Local oxygen homeostasis during various neuronal network activity states in the mouse hippocampus. J. Cereb. Blood Flow Metab. doi: 10.1177/ 0271678X17740091 [Epub ahead of print].

Schoknecht, K., Berndt, N., Rösner, J., Heinemann, U., Dreier, J. P., Kovács, R., et al. (2017). Event-Associated oxygen consumption rate increases ca. five-fold when interictal activity transforms into seizure-like events In Vitro. Int. J. Mol. Sci. 18:E1925. doi: 10.3390/ijms18091925

Schridde, U., Khubchandani, M., Motelow, J. E., Sanganahalli, B. G., Hyder, F., and Blumenfeld, H. (2008). Negative BOLD with large increases in neuronal activity. Cereb. Cortex 18, 1814-1827. doi: 10.1093/cercor/bhm208

Schuchmann, S., Albrecht, D., Heinemann, U., von Bohlen, and Halbach, O. (2002). Nitric oxide modulates low-Mg2 + -induced epileptiform activity in rat hippocampal-entorhinal cortex slices. Neurobiol. Dis. 11, 96-105. doi: 10.1006/ nbdi. 2002.0533

Schuchmann, S., Buchheim, K., Meierkord, H., and Heinemann, U. (1999). A relative energy failure is associated with low- $\mathrm{Mg} 2+$ but not with 4 aminopyridine induced seizure-like events in entorhinal cortex. J. Neurophysiol. 81, 399-403. doi: 10.1152/jn.1999.81.1.399

Schuchmann, S., Kovács, R., Kann, O., Heinemann, U., and Buchheim, K. (2001). Monitoring $\mathrm{NAD}(\mathrm{P}) \mathrm{H}$ autofluorescence to assess mitochondrial metabolic functions in rat hippocampal-entorhinal cortex slices. Brain Res. Brain Res. Protoc. 7, 267-276. doi: 10.1016/S1385-299X(01)00080-0

Schulz, S. B., Klaft, Z. J., Rösler, A. R., Heinemann, U., and Gerevich, Z. (2012). Purinergic P2X, P2Y and adenosine receptors differentially modulate hippocampal gamma oscillations. Neuropharmacology 62, 914-924. doi: 10. 1016/j.neuropharm.2011.09.024

Shao, L. R., and Stafstrom, C. E. (2017). Glycolytic inhibition by 2-deoxy-d-glucose abolishes both neuronal and network bursts in an in vitro seizure model. J. Neurophysiol. 118, 103-113. doi: 10.1152/jn.00100.2017

Sinning, A., and Hübner, C. A. (2013). Minireview: $\mathrm{pH}$ and synaptic transmission. FEBS Lett. 587, 1923-1928. doi: 10.1016/j.febslet.2013.04.045

Sotelo-Hitschfeld, T., Niemeyer, M. I., Mächler, P., Ruminot, I., Lerchundi, R., Wyss, M. T., et al. (2015). Channel-mediated lactate release by $\mathrm{K}^{+}$-stimulated astrocytes. J. Neurosci. 35, 4168-4178. doi: 10.1523/JNEUROSCI.5036-14.2015

Stafstrom, C. E., Ockuly, J. C., Murphree, L., Valley, M. T., Roopra, A., and Sutula, T. P. (2009). Anticonvulsant and antiepileptic actions of 2-deoxy-D-glucose in epilepsy models. Ann. Neurol. 65, 435-447. doi: 10.1002/ana.21603

Stafstrom, C. E., Roopra, A., and Sutula, T. P. (2008). Seizure suppression via glycolysis inhibition with 2-deoxy-D-glucose (2DG). Epilepsia 49(Suppl. 8), 97-100. doi: 10.1111/j.1528-1167.2008.01848.x

Streijger, F., Scheenen, W. J., van Luijtelaar, G., Oerlemans, F., Wieringa, B., and Van der Zee, C. E. (2010). Complete brain-type creatine kinase deficiency in mice blocks seizure activity and affects intracellular calcium kinetics. Epilepsia 51, 79-88. doi: 10.1111/j.1528-1167.2009.02182.x

Suh, M., Bahar, S., Mehta, A. D., and Schwartz, T. H. (2005). Temporal dependence in uncoupling of blood volume and oxygenation during interictal epileptiform events in rat neocortex. J. Neurosci. 25, 68-77. doi: 10.1523/JNEUROSCI.282304.2005

Szewczyk, A., Skalska, J., Głab, M., Kulawiak, B., Malińska, D., KoszelaPiotrowska, I., et al. (2006). Mitochondrial potassium channels: from pharmacology to function. Biochim. Biophys. Acta 1757, 715-720. doi: 10.1016/ j.bbabio.2006.05.002

Szybala, C., Pritchard, E. M., Lusardi, T. A., Li, T., Wilz, A., Kaplan, D. L., et al. (2009). Antiepileptic effects of silk-polymer based adenosine release in kindled rats. Exp. Neurol. 219, 126-135. doi: 10.1016/j.expneurol.2009.05.018

Takano, T., Tian, G. F., Peng, W., Lou, N., Lovatt, D., Hansen, A. J., et al. (2007). Cortical spreading depression causes and coincides with tissue hypoxia. Nat. Neurosci. 10, 754-762. doi: 10.1038/nn1902 
Tang, C. M., Dichter, M., and Morad, M. (1990). Modulation of the N-methylD-aspartate channel by extracellular $\mathrm{H}+$. Proc. Natl. Acad. Sci. U.S.A. 87, 6445-6449. doi: 10.1073/pnas.87.16.6445

Thomsen, K., Piilgaard, H., Gjedde, A., Bonvento, G., and Lauritzen, M. (2009). Principal cell spiking, postsynaptic excitation, and oxygen consumption in the rat cerebellar cortex. J. Neurophysiol. 102, 1503-1512. doi: 10.1152/jn.00289. 2009

Thornton, R. C., Rodionov, R., Laufs, H., Vulliemoz, S., Vaudano, A., Carmichael, D., et al. (2010). Imaging haemodynamic changes related to seizures: comparison of EEG-based general linear model, independent component analysis of fMRI and intracranial EEG. Neuroimage 53, 196-205. doi: 10.1016/j.neuroimage.2010.05.064

Tolner, E. A., Hochman, D. W., Hassinen, P., Otáhal, J., Gaily, E., Haglund, M. M., et al. (2011). Five percent CO2 is a potent, fast-acting inhalation anticonvulsant. Epilepsia 52, 104-114. doi: 10.1111/j.1528-1167.2010. 02731.x

Trussell, L. O., and Jackson, M. B. (1987). Dependence of an adenosineactivated potassium current on a GTP-binding protein in mammalian central neurons. J. Neurosci. 7, 3306-3316. doi: 10.1523/JNEUROSCI.07-10-03306. 1987

Tyvaert, L., LeVan, P., Dubeau, F., and Gotman, J. (2009). Noninvasive dynamic imaging of seizures in epileptic patients. Hum. Brain Mapp. 30, 3993-4011. doi: $10.1002 / \mathrm{hbm} .20824$

Urban, A., Golgher, L., Brunner, C., Gdalyahu, A., Har-Gil, H., Kain, D., et al. (2017). Understanding the neurovascular unit at multiple scales: advantages and limitations of multi-photon and functional ultrasound imaging. Adv. Drug Deliv. Rev. 119, 73-100. doi: 10.1016/j.addr.2017. 07.018

Van Gompel, J. J., Bower, M. R., Worrell, G. A., Stead, M., Chang, S. Y., Goerss, S. J., et al. (2014). Increased cortical extracellular adenosine correlates with seizure termination. Epilepsia 55, 233-244. doi: 10.1111/epi.12511

Vielhaber, S., Von Oertzen, J. H., Kudin, A. F., Schoenfeld, A., Menzel, C., Biersack, H. J., et al. (2003). Correlation of hippocampal glucose oxidation capacity and interictal FDG-PET in temporal lobe epilepsy. Epilepsia 44, 193-199. doi: 10.1046/j.1528-1157.2003.38102.x

Wei, A. C., Aon, M. A., O’Rourke, B., Winslow, R. L., and Cortassa, S. (2011). Mitochondrial energetics, $\mathrm{pH}$ regulation, and ion dynamics: a computationalexperimental approach. Biophys. J. 100, 2894-2903. doi: 10.1016/j.bpj.2011.05. 027

Wemmie, J. A., Taugher, R. J., and Kreple, C. J. (2013). Acid-sensing ion channels in pain and disease. Nat. Rev. Neurosci. 14, 461-471. doi: 10.1038/nrn3529

Winkler, E. A., Bell, R. D., and Zlokovic, B. V. (2011). Central nervous system pericytes in health and disease. Nat. Neurosci. 14, 1398-1405. doi: 10.1038/nn. 2946
Xiong, Z. Q., Saggau, P., and Stringer, J. L. (2000). Activity-dependent intracellular acidification correlates with the duration of seizure activity. J. Neurosci. 20, 1290-1296. doi: 10.1523/JNEUROSCI.20-04-01290.2000

Yaseen, M. A., Sutin, J., Wu, W., Fu, B., Uhlirova, H., Devor, A., et al. (2017). Fluorescence lifetime microscopy of NADH distinguishes alterations in cerebral metabolism in vivo. Biomed. Opt. Express. 8, 2368-2385. doi: 10.1364/BOE.8. 002368

Yemisci, M., Gursoy-Ozdemir, Y., Vural, A., Can, A., Topalkara, K., and Dalkara, T. (2009). Pericyte contraction induced by oxidative-nitrative stress impairs capillary reflow despite successful opening of an occluded cerebral artery. Nat. Med. 15, 1031-1037. doi: 10.1038/nm.2022

Young, D., and Dragunow, M. (1994). Status epilepticus may be caused by loss of adenosine anticonvulsant mechanisms. Neuroscience 58, 245-261. doi: 10.1016/ 0306-4522(94)90032-9

Zhao, M., Ma, H., Suh, M., and Schwartz, T. H. (2009). Spatiotemporal dynamics of perfusion and oximetry during ictal discharges in the rat neocortex. J. Neurosci. 29, 2814-2823. doi: 10.1523/JNEUROSCI.4667-08.2009

Zhao, M., Nguyen, J., Ma, H., Nishimura, N., Schaffer, C. B., and Schwartz, T. H. (2011). Preictal and ictal neurovascular and metabolic coupling surrounding a seizure focus. J. Neurosci. 31, 13292-13300. doi: 10.1523/JNEUROSCI.2597-11. 2011

Ziemann, A. E., Schnizler, M. K., Albert, G. W., Severson, M. A., Howard, M. A. III, Welsh, M. J., et al. (2008). Seizure termination by acidosis depends on ASICla. Nat. Neurosci. 11, 816-822. doi: 10.1038/nn.2132

Zonta, M., Angulo, M. C., Gobbo, S., Rosengarten, B., Hossmann, K. A., Pozzan, T., et al. (2003). Neuron-to-astrocyte signaling is central to the dynamic control of brain microcirculation. Nat. Neurosci. 6, 43-50. doi: 10.1038/nn980

Zsurka, G., and Kunz, W. S. (2015). Mitochondrial dysfunction and seizures: the neuronal energy crisis. Lancet Neurol. 14, 956-966. doi: 10.1016/S14744422(15)00148-9

Zubler, F., Steimer, A., Gast, H., and Schindler, K. A. (2014). Seizure termination. Int. Rev. Neurobiol. 114, 187-207. doi: 10.1016/B978-0-12-418693-4.00008-X

Conflict of Interest Statement: The authors declare that the research was conducted in the absence of any commercial or financial relationships that could be construed as a potential conflict of interest.

Copyright (c) 2018 Kovács, Gerevich, Friedman, Otáhal, Prager, Gabriel and Berndt. This is an open-access article distributed under the terms of the Creative Commons Attribution License (CC BY). The use, distribution or reproduction in other forums is permitted, provided the original author(s) and the copyright owner(s) are credited and that the original publication in this journal is cited, in accordance with accepted academic practice. No use, distribution or reproduction is permitted which does not comply with these terms. 